\title{
Análisis de la evolución reciente del sector externo salvadoreño
}

Roberto Góchez y Melissa Salgado

Departamento de Economía UCA, San Salvador

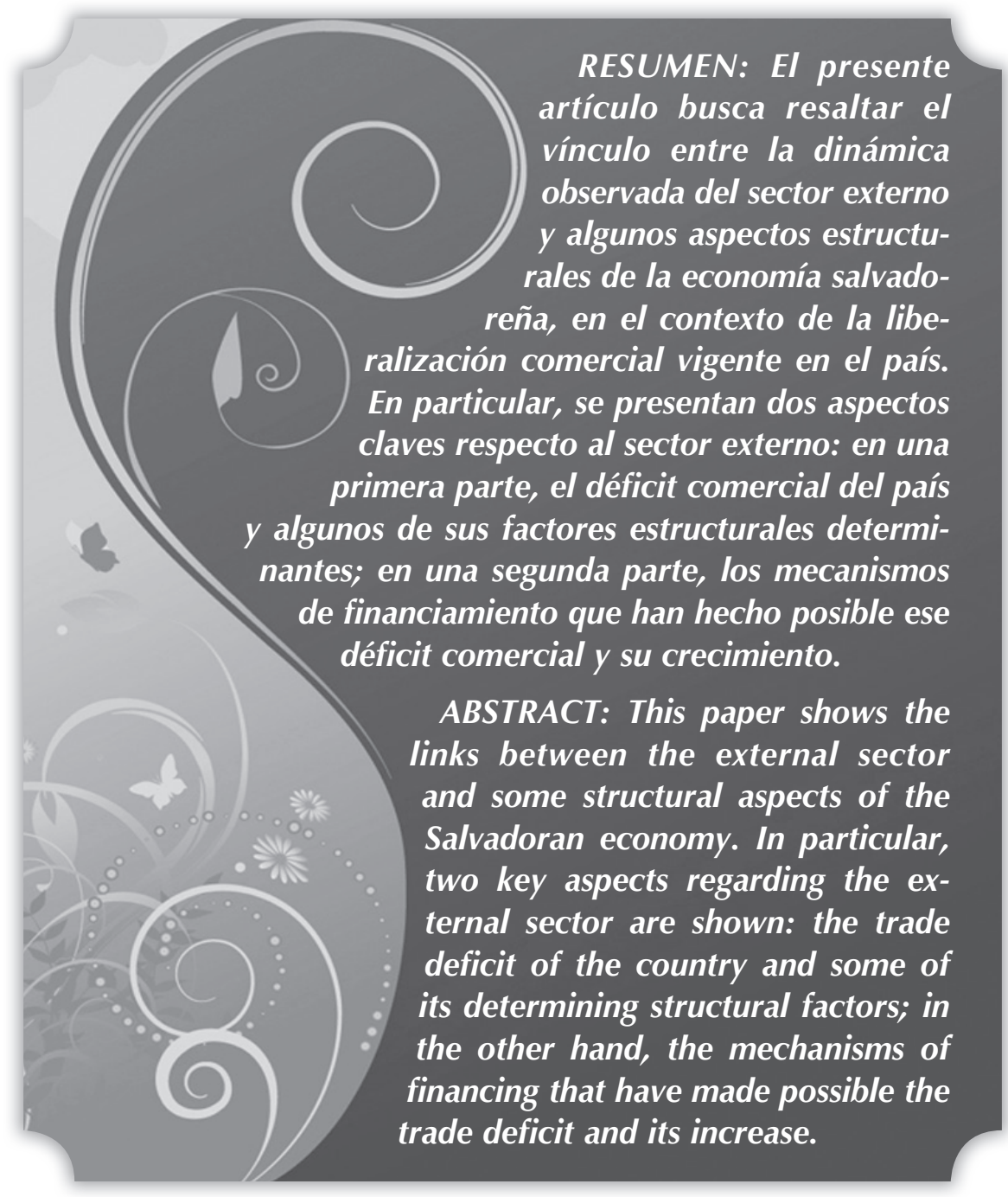


L

a evolución del sector externo salvadoreño ha reflejado históricamente diferentes rasgos estructurales de la economía capitalista nacional, los cuales se ven fuertemente influidos por el tipo específico de inserción en el sistema capitalista mundial que se ha establecido en cada época. Asimismo, la estructura económica nacional es influenciada por la economía mundial, que lo hace por medio del desempeño del sector externo, mediado por el tipo de inserción externa particular que ha existido en cada momento. Es decir, el sector externo y su evolución reflejan rasgos estructurales de la economía nacional, pero también son el canal por medio del cual la economía mundial influye a la del país. En ello tiene un peso importante el tipo específico de inserción externa que El Salvador ha tenido en cada momento.

El modelo neoliberal actualmente vigente a escala mundial y nacional, se empezó a instaurar a nivel internacional desde los años ochenta, promoviendo, entre otras cosas un esquema de inserción externa que ha privilegiado la receta de la liberalización y desregulación económica externa -flujos comerciales y movimientos de capitalpara todos los países del mundo, sin importar los grados de desarrollo de las economías particulares.
En El Salvador los promotores del modelo neoliberal aplicaron dicho esquema de liberalización y desregulación externa en el país, a partir de 1990 por más de veinte años, a través de cuatro mecanismos principalmente: procesos unilaterales de apertura comercial - desgravación comercial y eliminación de barreras no arancelarias- de los gobiernos nacionales, condicionados en muchos casos por los programas de ajuste estructural; el relanzamiento de los procesos de integración económica regional con un esquema librecambista; aplicación de acuerdos multilaterales que favorecen la liberalización comercial, como los emanados de la Organización Mundial de Comercio, OMC; y más recientemente por acuerdos bilaterales, como han sido los Tratados de Libre Comercio (TLC), que contienen, entre otras cosas, esquemas de liberalización comercial reciproca —eliminación total y recíproca de los aranceles-y liberalización de flujos de inversiones.

Es fundamental, después de más de veinte años de neoliberalismo y con el reciente cambio de gobierno en El Salvador, revalorar profundamente el proceso de liberalización mismo, tanto en el plano teórico como por sus resultados, buscando establecer principalmente el vínculo entre dicho proceso 
de liberalización con los desafíos del desarrollo económico y social: equidad, crecimiento y estabilidad.

En línea con lo señalado en el párrafo previo, el presente artículo busca resaltar el vínculo entre la dinámica observada del sector externo y algunos aspectos estructurales de la economía salvadoreña, en el contexto de la liberalización comercial vigente en el país. En particular, se presentan dos aspectos claves respecto al sector externo: en una primera parte, el déficit comercial del país y algunos de sus factores estructurales determinantes; en una segunda parte, los mecanismos de financiamiento que han hecho posible ese déficit comercial y su crecimiento. Aquí se analizan ambos aspectos, estrechamente interrelacionados, haciendo énfasis en su evolución para el período más reciente que comprende desde el año 2000 al 2009.

\section{Desempeño de la balanza comercial, tipo de cambio real, salarios y productividad}

En este primer apartado se presenta, en primer lugar, la evolución de los principales aspectos del sector externo, como el déficit comercial, exportaciones e importaciones y tipo de cambio real entre 2000-2009. En segundo lugar, se introducen de manera breve, interpretaciones enfrentadas sobre los efectos del comercio liberalizado en una economía atrasada como la salvadoreña. $Y$ como un tercer aspecto, se analizan algunas variables provenientes del marco teórico alterno clásico-marxista del comercio internacional, que subraya algunos de los aspectos estructurales que han estado a la base del déficit comercial y la apreciación del tipo de cambio real que ha experimentado El Salvador.

\subsection{Desequilibrios comerciales y apreciación del tipo de cambio real}

Durante los últimos veinte años la economía salvadoreña ha mantenido un creciente déficit comercial con el mundo. Esta tendencia se ha debido, por un lado, a la incapacidad de la economía salvadoreña para incrementar sustancialmente sus exportaciones dado el abultado aumento de sus importaciones. Este incremento de la brecha comercial, relacionado al mencionado comportamiento de las exportaciones e importaciones del país, ha estado influido por una apreciación de largo plazo del tipo de cambio real (ITCER) de El Salvador respecto al mundo -decrecimiento del ITCER-, que significa un enca- 
recimiento relativo de los bienes salvadoreños frente a los extranjeros, lo cual representa una pérdida de competitividad de las empresas locales frente a las foráneas. ${ }^{2}$

Las anteriores tendencias de largo plazo de la economía salvadoreña pueden observarse también para los últimos años, en los gráficos que se muestran a continuación. El gráfico 1a muestra el creciente déficit comercial (incluyendo maquila) de El Salvador, así como el menor nivel y menor dinamismo de sus exportaciones totales con maquila neta respecto a las importaciones no maquileras, entre el primer trimestre de 1999 (I/99) y el cuarto del 2009 (IV/2009). El gráfico 1b muestra el índice de tipo de cambio efectivo real (ITCER) de El Salvador con el mundo (global), por un lado, y con Estados Unidos, por el otro; ambos indicadores del ITCER coinciden en mostrar una apreciación - trayectoria decreciente del ITCER - que refleja el encarecimiento relativo de los bienes que ha padecido el país respecto al mundo y a la nación norteamericana entre el primer trimestre del 2000 y el cuarto trimestre del 2009.

Gráfico 1a

Exportaciones con maquila neta, importaciones no maquileras y déficit comercial total trimestrales

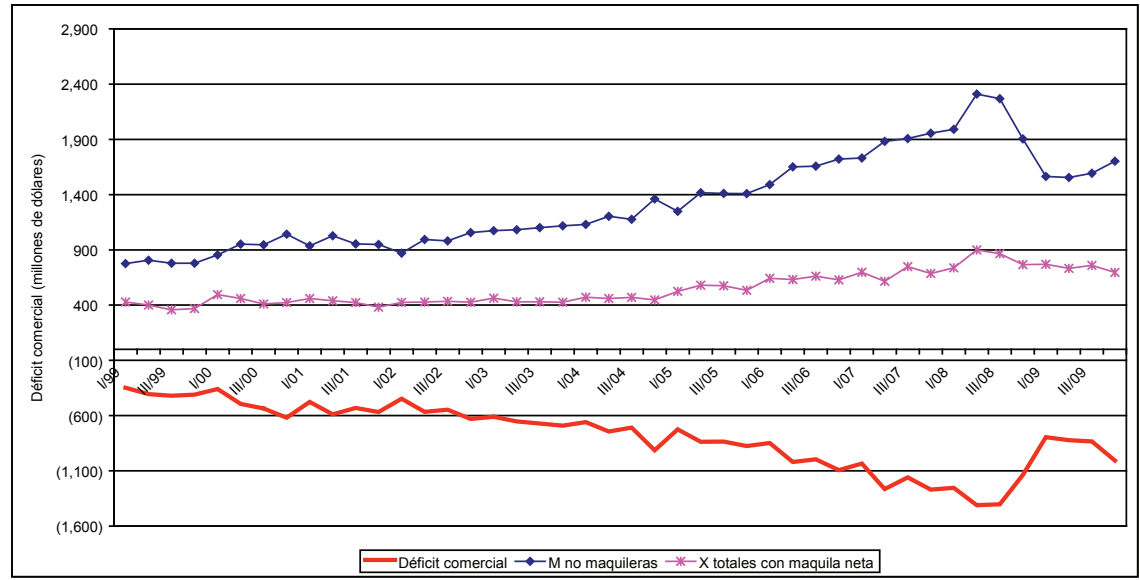

Nota: $M$ no maquileras se refiere a importaciones sin incluir maquila; $X$ totales con maquila neta incluyen las no maquileras y las netas de maquila; las exportaciones netas de maquila se refieren al saldo de las exportaciones totales de maquila menos las importaciones de la misma; déficit comercial es exportaciones totales con maquila neta menos importaciones no maquileras. 


\section{Gráfico 1b}

Índice trimestral de tipo de cambio efectivo real global y bilateral

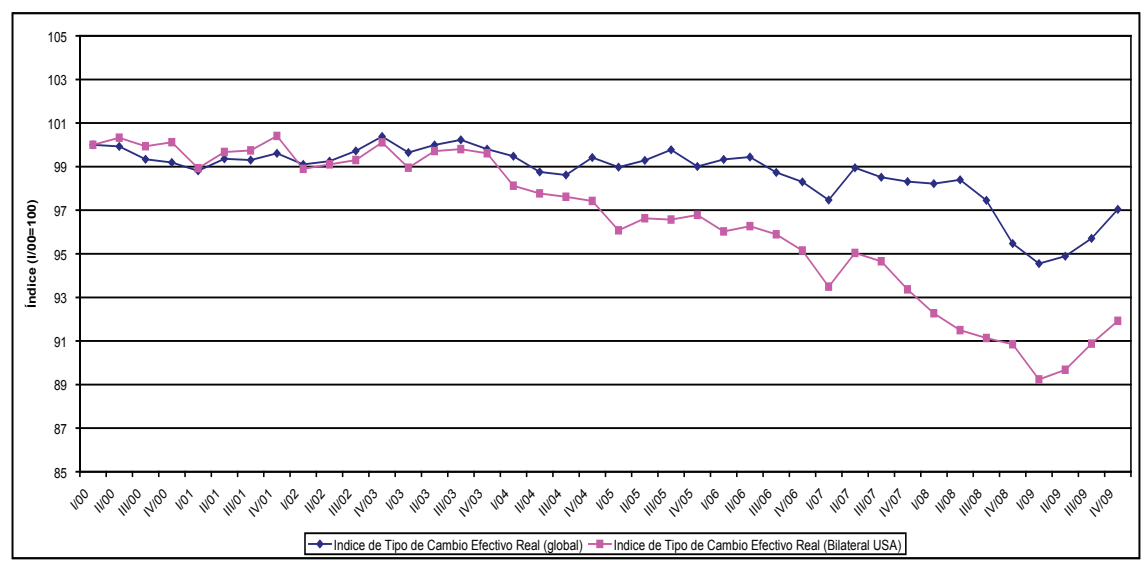

Nota: Un aumento del Índice de Tipo de Cambio Efectivo Real significa un encarecimiento relativo de los bienes y servicios extranjeros frente a los salvadoreños; por el contrario una reducción del Índice de Tipo de Cambio Efectivo Real significa un encarecimiento relativo de los bienes y servicios salvadoreños frente a los extranjeros. Los ITCER presentados aquí son una rebasificación de los calculados por el BCR. Fuente: Elaboración propia, a partir dedatos del BCR disponibles en línea en http://www.bcr. gob.sv . [Consultado en febrero de 2010]

No obstante las tendencias anteriormente señaladas de la balanza comercial y del ITCER, en los gráficos 1 a y $1 \mathrm{~b}$ puede observarse que durante el período recesivo mundial del 2009, el déficit comercial salvadoreño ha disminuido mientras que el tipo de cambio real se ha depreciado - es decir ha aumentado su valor respecto al último trimestre del 2008-. Esto significa que el proceso recesivo ha supuesto un cierto alivio sobre la tendencia de largo plazo de pérdida de competitividad de los bienes salvadoreños y de aumento del saldo deficitario de la balanza comercial. Hay que anotar que esto último puede deberse más que al buen desempeño de la economía salvadoreña, al efecto de la contracción de la actividad económica nacional, mundial y norteamericana sobre los flujos comerciales y a la deflación de precios ocurrida en ese contexto. En particular, durante este período recesivo las importaciones se han contraído más que las exportaciones del país, en buena medida debido al efecto sobre las primeras de la reducción del ingreso nacional y de la actividad económica local, en el contexto de la enorme dependencia de bienes extranjeros que tiene la economía salvadoreña. 


\subsection{Concepciones opuestas sobre el comercio liberalizado para una nación atrasada}

La tendencia anteriormente descrita de la balanza comercial y el tipo de cambio real, si bien es reconocida ampliamente como un hecho, encuentra diferentes explicaciones teóricas y empíricas y por ende recomendaciones de política para superarla. En particular, la liberalización y desregulación comercial ocurridas al amparo neoliberal, se han fundamentado teóricamente en la doctrina de las ventajas comparativas, en sus versiones ricardianas y neoclásicas, que suponen que el libre comercio producirá una situación de beneficio generalizado en los países que lo aplican, incluso para una nación por muy atrasada que fuera. Las ganancias supuestas en el largo plazo por la ventaja comparativa para los países son: mejora de la eficiencia por la especialización, aumento del consumo por encima de lo posible en autarquía, un bienestar mayor o que potencialmente puede serlo, pleno empleo previo y posterior al libre comercio, garantía de especialización en ciertos bienes - al menos uno- y equilibrio comercial, e incluso algunos de los modelos más populares suponen convergencia internacional de salarios y tasas de beneficio. Desde esta visión, para poder cosechar la mayor parte de los beneficios mencionados sin importar cuán atrasado o ineficiente en términos productivos sea un país respecto a otras naciones, ni cuán persistente sea dicha brecha.

La doctrina de la ventaja comparativa reconoce que con la liberalización ciertos países participantes podrían obtener mayores beneficios que otros, e incluso que alguno de ellos podría no obtener ninguno, además reconoce que en el corto plazo puede haber efectos negativos o costos importantes. Sin embargo, dicha teoría descarta tajantemente que cualquiera de los países pudiera padecer efectos netos negativos en el largo plazo, una vez que se han dado todos los ajustes. Los modelos más importantes de ventaja comparativa descartan por hipótesis que el comercio liberalizado pudiera generar, en el largo plazo, para un país efectos tales como: desempleo crónico, pérdida sistemática de la competitividad, destrucción sistemática e irreversible de su aparato productivo y exportador, ampliación de la brecha comercial, crisis cambiarias, caídas sostenidas de salarios reales y ganancias, acrecentamiento de la brecha internacional de salarios y ganancias, entre otras.

El motivo por el que los modelos de ventajas comparativas asumen que el comercio liberalizado será beneficioso y que no tendría efectos negativos, es que suponen explícita o implícitamente, que operan mecanismos de mercado a nivel internacional que garantizarán siempre que todos los países 
puedan especializarse y exportar algunos bienes - aquellos en los que posean ventaja comparativaincluso aquellas naciones más atrasadas e ineficientes. En particular, la ventaja comparativa asume que con libre comercio un país que tiene un déficit comercial en un inicio, verá que sus precios/costos bajarán, aumentarán sus exportaciones y disminuirán sus importaciones, disminuyendo así su déficit; por el otro lado, el país con superávit comercial, por el contrario, verá que sus precios/costos suben, disminuyendo sus exportaciones y aumentando sus importaciones, bajando así su superávit; ese movimiento se mantendrán hasta que se equilibre la balanza comercial de ambos. Para la ventaja comparativa los términos de intercambio o tipo de cambio real de equilibrio con libre comercio de una nación, es decir el precio de sus bienes respecto a los extranjeros, son aquellos con los cuales se da el equilibrio comercial ${ }^{3}$

Por ejemplo, la ventaja comparativa reconoce la posibilidad que un país subdesarrollado, ${ }^{4}$ que hipotéticamente produjera todos sus bienes más caros que sus contrapartes debido a sus desventajas tecnológicas, al liberalizarse podría experimentar un déficit comercial inicial. Sin embargo, asume que por mecanismos automáticos de mercado se abaratarán algunos de sus bienes, hasta el punto de llegar a producir al menos uno más barato que sus adversarios. Ese mecanismo le estaría garantizado a dicho país que siempre, por ineficiente que fuera en todo, con la liberalización comercial encontrará al menos un bien que exportar —aquel en que fuera menos peor-. Pero el mecanismo supuesto, no se detiene ahí. El país atrasado, teniendo ahora al menos un bien que exportar, pero aun con déficit comercial, vería que sus términos de intercambio y/o tipos de cambio real - precio relativo de sus bienes respecto el extranjero- se depreciarán, es decir se seguirán abaratando sus bienes respecto a los de sus adversarios. Ese movimiento de precios y tipos de cambio reales asociados, mejoraría la competitividad de las exportaciones del país atrasado y desmejoraría la de los bienes importados desde el país adelantado, haciendo que eventualmente estos flujos sean de una cuantía suficiente para equilibrar el saldo comercial de todas las naciones participantes. ${ }^{5}$

Como se ve para la ventaja comparativa la economía subdesarrollada absolutamente ineficiente que se liberaliza, con el paso del tiempo vería como gracias a las fuerzas automáticas del mercado - mecanismos monetarios autocorrectores - es protegida y equiparada frente a las naciones más adelantadas, con una fuerza capaz de equilibrar su saldo comercial, sin ser imprescindible que tenga que haber superado tecnológicamente a sus competidores. ${ }^{6}$ 
Al anterior planteamiento, la concepción convencional del comercio internacional le agrega la teoría de la paridad del poder de compra (PPA), en su versión absoluta o relativa, que combinado con algunas extensiones monetarias, supondría que posterior a un hipotético equilibrio de libre comercio, una economía rezagada tampoco sufrirá un encarecimiento sostenido de sus bienes respecto a los de sus socios -por motivos monetarios-, es decir, apreciaciones sostenidas del tipo de cambio real, pues éste se debería mantener constante u oscilando en sus valores de equilibrio. ${ }^{7}$

En resumen, los planteamientos de la ventaja comparativa y la paridad del poder de compra (PPA) que están a la base de la concepción convencional predominante de la economía internacional, descartan teóricamente que un país atrasado con el comercio liberalizado pudiera experimentar sistemáticamente en el largo plazo un encarecimiento relativo de sus bienes -apreciación sistemática de su tipo de cambio real-, pérdida de cuotas frente a sus competidores y un empeoramiento de su déficit de balanza comercial. Tanto la ventaja comparativa como la PPA, por su concepción de los tipos de cambio real, ofrecen una visión idealizada del comercio internacional liberalizado en el mundo capitalista, ya que el mismo se presenta como una posibilidad de ganar-ganar, y en el peor de los casos como una opción sin consecuencias negativas para cualquier país, incluso para los más atrasados.

A partir de lo anterior, se puede entender que el creciente déficit de la balanza comercial y de la apreciación del tipo de cambio real ocurridos con la liberalización comercial en una economía atrasada como la de El Salvador, resultarían paradójicos para los promotores del esquema liberalizador —neoliberales-, ya que contradice lo que suponen debería ocurrir según "la teoría" ${ }^{8}$

Algunas de las explicaciones más elaboradas que, sin salirse del esquema neoclásico, intentan dar respuesta a tal paradoja vendrían por identificar el mal holandés, que consistiría, en el caso de El Salvador, en que los flujos crecientes de remesas han encarecido los bienes locales debido al incremento de la demanda derivada de las mismas (Rivera. 2000). Otras explicaciones aludirían a que, en realidad, el libre mercado no funciona como debería por diferentes imperfecciones de mercado. Por ejemplo, se suele citar las rigideces de precios — entre ellas, se suele mencionar la inflexibilidad de los salarios- o en algunos casos se suele mencionar algún tipo negligencia empresarial y gubernamental, que les impide a las empresas aprovechar lo beneficios supuestos del comercio liberalizado. Otras explicaciones aducen la ausencia de algún tipo de "nuevos 
factores", en los cuales encuentra lugar casi cualquier aspecto que se considera beneficia al capital — privatización de servicios públicos, mayor apertura comercial, leyes de propiedad intelectual, bajas tasas de interés, remoción de regulaciones a la inversión extranjera, seguridad jurídica, "cultura exportadora", etc.— 9

Las explicaciones anteriores, si bien pueden aportar elementos que influyen, tienen en común que implícita o explícitamente ubican el problema de los desequilibrios sostenidos del sector externo y apreciación cambiaria salvadoreña en algún aspecto exógeno y perturbador al funcionamiento de la economía real y productiva o del libre mercado/comercio. Es decir, esas explicaciones no consideran la posibilidad que lo que ha ocurrido sea precisamente la dinámica propia que tiene el comercio internacional capitalista para un país atrasado en términos productivos como $\mathrm{El} \mathrm{Sal-}$ vador, que se inserta en el mundo actual a través de una liberalización comercial amplia y profunda, sin revertir tal situación de atraso.

En contraste con la ventaja comparativa el enfoque alternativo, Ilamado teoría de la ventaja absoluta de costos, de corte clásicomarxista (Shaikh, 1991a, 1991b; Guerrero, 1995), ${ }^{10}$ ha buscado poner al centro del análisis que la evolución de largo plazo del saldo comercial y el tipo de cambio real de un país en el contexto capitalista mundial, están determinados por factores estructurales, que operan de una forma más "pura" en un entorno comercial más liberalizado: ${ }^{11}$ la capacidad competitiva real de sus capitales frente a sus adversarios externos, y la evolución de dicho aspecto. Esto último hace referencia a la capacidad efectiva de las empresas ubicadas en un país para quitarle cuotas de mercado a sus rivales y aumentar así sus ganancias a través de: producir diversos tipos de bienes y servicios, hacerlo a menores costos y/o con mejor calidad que sus adversarios. Desde esta visión, es claro que pueden influir aspectos de políticas públicas y del entorno, que pueden potenciar o anular esa capacidad competitiva, pero que por sí mismos no otorgarían capacidad competitiva real en el caso que una economía carezca de capacidad productiva. ${ }^{12}$

En el capitalismo las empresas buscan adquirir ventajas competitivas lo cual comienza con la acumulación de capital tendiente a introducir mejoras tecnológicas y organizativas en la producción - $\mathrm{O}$ de una manera más general revolucionar las fuerzas productivas-, que mejoren la calidad de los productos y reduzcan sus costos de reproducción, con el objetivo de superar a sus adversarios. Ese proceso se extiende a la circulación misma, en donde las empresas buscan, de manera similar, aplicar todo tipo de estrategias - publicidad, transporte, comercialización, financiamiento, 
entre otras - para quitarle cuotas de mercado a sus rivales (Guerrero, 1995: 16-17). Esta competencia se Ileva a cabo tanto a nivel nacional como internacional, si bien en el ámbito mundial la misma tiene mayor complejidad debido a la existencia de mayores restricciones a los flujos de bienes y servicios y a la existencia de diversas divisas.

Para el enfoque clásico-marxista, un país atrasado, que tenga una amplia desventaja por parte de sus empresas respecto a los países desarrollados, y que se liberalice en esas condiciones, verá muy seguramente aparecer un déficit comercial por producto y en general. Ese déficit comercial reflejará por lo general la desventaja competitiva de las empresas del país atrasado en diferentes ramas respecto a sus adversarios de otras naciones, ${ }^{13}$ ya sea por inferior calidad, menor variedad/diversidad o mayores costos de los bienes y servicios producidos localmente.

Adicionalmente el enfoque clásico-marxista sostiene que en el largo plazo, el deterioro de la balanza comercial —disminución del superávit o aumento del déficit-y la apreciación del tipo de cambio real que puede experimentar una nación atrasada serán igualmente la consecuencia de una evolución desventajosa de su competitividad, entendida como el encarecimiento relativo de largo plazo de los costos de producción de una amplia gama de los bienes y servicios producidos por los capitales locales respecto a los de otras economías. ${ }^{14}$ Dicha tendencia se verá por lo general complementada por influjos de capital en sentido contrario - endeudamiento y flujos de capital de cartera que aprovecharán las necesidades de financiamiento del país deficitario para obtener ganancias mayores que en sus países de origen-que pueden permitirle a las economías deficitarias financiar la creciente brecha comercial, y que evitan en la práctica que operen mecanismos que equilibran la balanza comercial, tal como lo supone la teoría de la ventaja comparativa. ${ }^{15}$

Los aspectos de largo plazo señalados por el enfoque clásicomarxista, sin embargo, no excluyen otra serie de factores que pueden acentuar o perturbar dicha relación: corridas cambiarias, crisis de balanza de pagos y el ciclo económico; o como en el caso de El Salvador y otras naciones subdesarrolladas, el aparecimiento de flujos de remesas de trabajadores pueden Ilenar las necesidades de financiamiento de su déficit externo.

Lo anterior quiere decir que, para la teoría clásico-marxista, una economía atrasada que parta de una situación inicial en la cual la mayoría de sus capitales de las diferentes ramas se encuentran rezagados en cuanto a su capacidad competitiva, que no logren revertir tal situación, con la liberalización comercial muy 
seguramente mostrará tendencias a disminuir sus cuotas de mercado, a tener y aumentar su déficit comercial, a la apreciación cambiaria real - encarecimiento de sus bienes-, procesos de endeudamiento externo para financiar la brecha comercial, y posiblemente mayores problemas de quiebra de empresas y desempleo. ${ }^{16}$

Desde la óptica crítica el comercio internacional liberalizado, en el contexto capitalista, no necesariamente reparte beneficios para todos los países, ni tiende a permitirle a los más atrasados alcanzar el equilibrio comercial, ni tiene algo que automáticamente proteja a las economías y empresas más débiles y rezagadas, muchos menos garantizará el pleno empleo y buenos salarios a sus trabajadores. En el comercio internacional liberalizado bajo el sistema capitalista impera la ley del más fuerte, pues son las empresas con las mejores condiciones de reproducción las que se imponen al resto y aumentan sus cuotas de mercado a costa de sus rivales. Con el comercio liberalizado serán igualmente las naciones que posean un mayor número de capitales con ventajas competitivas las que se

ICLUR $=$ CLUR $* / C L U R$

CLUR* $^{*}=$ IwmeR*/Iproductividad*

CLUR=IwmeR/lproductividad impondrán comercialmente a las naciones que posean las empresas más rezagadas, muy a pesar de las consecuencias sociales al interior de las mismas.

\subsection{Un análisis crítico del desequi- librio comercial y de la aprecia- ción del tipo de cambio real de El Salvador}

Como se comprende de lo anterior, en el análisis clásico-marxista ocupa un lugar central el análisis de la tendencia de los costos unitarios de producción relativos de una economía respecto al mundo, que se encuentran estrechamente vinculados al proceso competitivo en una dimensión mundial. Tal cosa se puede hacer para el caso de El Salvador a través del indicador de los costos laborales unitarios reales relativos, que vendrían a ser una variable proxy de los costos de producción de cada país, los cuales a su vez son un aproximado de sus precios. ${ }^{17}$ En particular, el índice de los costos laborales unitarios reales relativos (ICLUR) se definen como el cociente del índice de los costos laborales unitarios reales extranjeros (CLUR*) y sus similares nacionales (CLUR): ${ }^{18}$

Es decir: 
En donde:

ICLUR es el cociente del índice costos laborales unitarios extranjeros respecto a los locales.

CLUR son los índices de costos laborales unitarios reales locales. Con asterisco $\left.{ }^{*}\right)$ son los mismos índices para el extranjero.

IwmeR son los índices de salarios medios reales locales, y con asterisco $\left({ }^{*}\right)$ para el extranjero.

Iproductividad: son los índices de productividad media del trabajo del país local. Con asterisco $\left(^{*}\right)$ son los mismos índices para el extranjero.

Dada la definición del índice de costos laborales unitarios reales relativos (ICLUR) como el cociente de los costos laborales unitarios reales extranjeros entre los locales, un crecimiento del mismo mostrará un encarecimiento relativo de los costos laborales unitarios reales extranjeros frente a los locales; por el contrario, un decremento del ICLUR muestra un encarecimiento relativo de los costos laborales unitarios reales locales frente a los extranjeros. ${ }^{19}$ Este indicador mostrará la evolución de los costos de las empresas de un país respecto a sus principales socios, a manera de constatar si la apreciación o depreciación de una economía tiene o no como su base una evolución rezagada de la competitividad de sus empresas.

En el gráfico 2a se presentan dos variantes del índice de costos laborales unitarios reales relativos de El Salvador respecto a Estados Unidos, ${ }^{20}$ su principal destino y origen de los flujos comerciales, con frecuencia trimestral. ${ }^{21}$ 
Gráfico 2a

Índices trimestrales de Costos laborales Unitarios Reales Relativos Manufactureros (ICLUR) y tipo de cambio real entre Estados Unidos-El Salvador

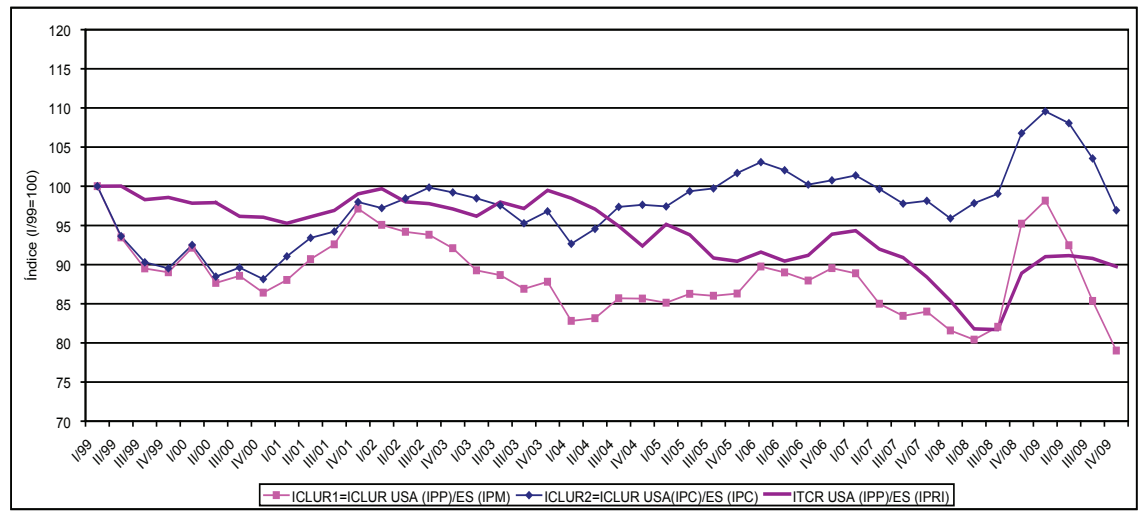

Nota: ICLUR USA(IPC)/ES (IPC) es el cociente del índice de costos laborales de Estados Unidos respecto a El Salvador, utilizando salarios deflactados por el índice de precios al consumidor. ICLUR USA(IPP)/ES(IPM) es el mismo cociente, pero utilizando salarios deflactados por el índice de precios al productor (IPP todos los bienes) de Estados Unidos y el índice de precios al por mayor de El Salvador. El ITCR USA(IPP)/ES(IPRI) es el índice de tipo de cambio real entre Estados Unidos y El Salvador, utilizando el índice de precios al productor (IPP manufacturas) y el índice de precios industriales (IPRI) de El Salvador.

\section{Gráfico 2b \\ Índices trimestrales de Salarios Medios Reales Manufactureros El Salvador-Estados Unidos ${ }^{22}$}

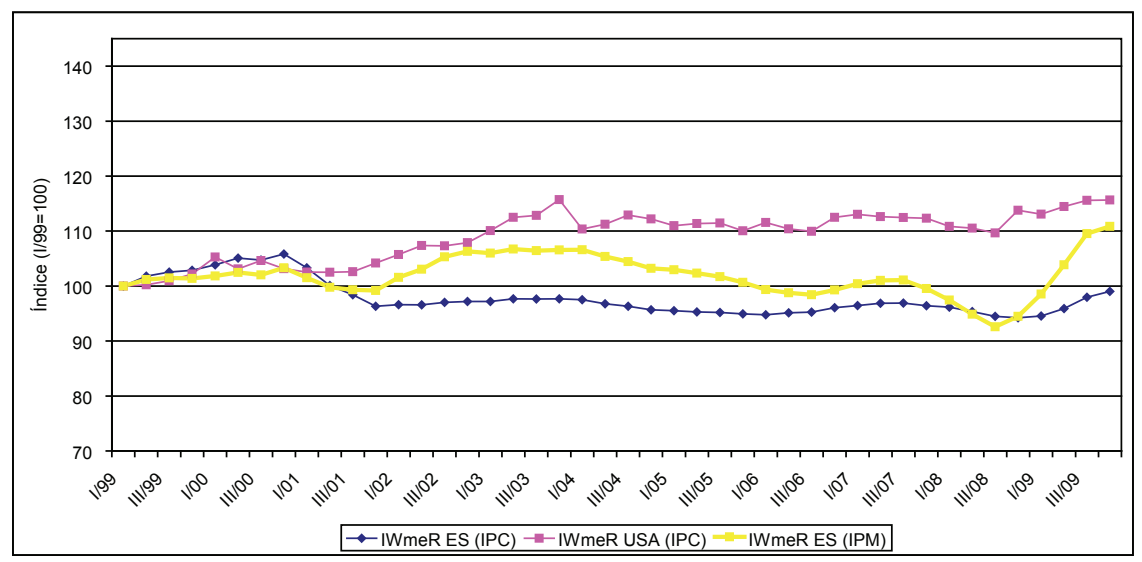


Nota: IwmeR ES (IPC) son los salarios reales de El Salvador deflactados por el índice de precios al consumidor (IPC); IWmeR USA (IPC) es la misma variable para Estados Unidos, deflactados por el IPC; IWmeR ES (IPM) son los salarios reales de El Salvador, pero deflactados utilizando el índice de precios al por mayor (IPM).

\section{Gráfico 2c}

\section{Índices trimestrales de Productividad Media de los trabajadores de la Manufactura El Salvador-Estados Unidos}

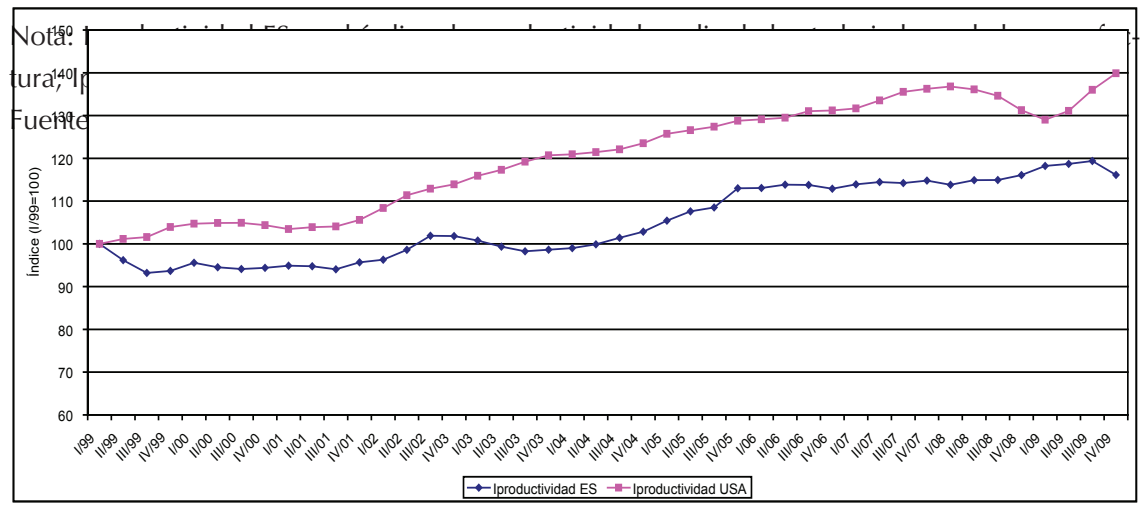

En el gráfico 2a se aprecia un primer indicador de los ICLUR que serían los costos laborales unitarios relativos Estados Unidos-El Salvador, estimados con los salarios reales deflactados con los índices de precios al productor para Estados Unidos y al por mayor para El Salvador (ICLUR USA(IPP)/ES(IPM)). Este indicador, que se denominará ICLUR1 por brevedad, muestra una tendencia a caer, que significa un encarecimiento relativo de los costos de producción de El Salvador frente a los de Estados Unidos. La tendencia de este ICLUR1 coincide con la tendencia a la apreciación del tipo de cambio real del país respecto a Estados Unidos, que se visualiza en la caída del indicador
ITCR USA(IPP)/ES(IPRI). ${ }^{23}$ Sin embargo, el ICLUR1 muestra una tendencia descendente más pronunciada.

La coincidencia en la tendencia del ICLUR1 y el ITCR entre El Salvador y Estados Unidos, sugieren al menos que el encarecimiento de los precios de los bienes salvadoreños mostrado por el ITCR tiene alguna base en la rezagada evolución de la capacidad competitiva de costos de las empresas salvadoreñas frente a las norteamericanas mostrado por el ICLUR1. Tanto el ITCR y los ICLUR1 bilaterales con Estados Unidos tuvieron un cambio momentáneo en su trayectoria para el reciente período contractivo de la economía (2008-2009), sin 
embargo, actualmente muestran señales de regresar a su tendencia "normal".

En el gráfico 2a se puede visualizar un segundo indicador de los ICLUR, que se denominará ICLUR2. Este indicador se ha calculado con los índices de precios al consumidor (IPC) de ambos países (ICLUR USA(IPC)/ES(IPC)) y muestra un cierta discrepancia respecto al ICLUR1.

Este segundo indicador (ICLUR2) muestra una tendencia más errática que el primero: inicialmente un encarecimiento relativo de los costos laborales de El Salvador respecto a Estados Unidos previo al 2001; luego muestra la tendencia inversa - un encarecimiento relativo de los costos norteamericanoshasta 2002 para mantenerse oscilando con altibajos alrededor del nivel inicial (100) hasta fines del 2008; a partir de este año, y en el marco del período recesivo mundial el ICLUR2 crece hasta el primer trimestre del 2009, mostrando que los costos de El Salvador se abaratan relativamente respecto a los norteamericanos, y luego se da un encarecimiento que los lleva a retornar a su mismo nivel inicial (100).

En resumen, este segundo indicador (ICLUR2), estimado con los respectivos IPC, difiere de los resultados del primer indicador (ICLUR1), mostrándose más errático y con cierta tendencia a crecer. Sin embargo si se observa con cuidado el ICLUR2 se ubica al final del período cerca del valor inicial de 100, y en parte su tendencia creciente se debe al efecto del repunte que tuvo en el 2009, en el marco del período recesivo mundial. Así la evolución del ICLUR2, si bien resulta menos negativa para el país que lo indicado por el ICLUR1, estaría mostrando que El Salvador no ha logrado una considerable reducción en sus costos laborales unitarios relativos. Este estancamiento en la competitividad de costos, mostrada por el ICLUR2, no es tampoco un consuelo, pues dado el rezago histórico y la profundización de la liberalización comercial de la última década, El Salvador necesitaría mantener por varios años progresos significativos en caso que esperará un mejor desempeño productivo y comercial. ${ }^{24}$

En suma, los anteriores resultados de los ICLUR tienen cierta sintonía con lo indicado por el ITCR, pues aportan evidencia en torno a que la apreciación cambiaria y el déficit comercial creciente se han visto influidos por una evolución desfavorable de la capacidad competitiva de costos o por los pocos progresos en ese aspecto - -según sea el ICLUR utilizado- de las empresas manufactureras salvadoreñas frente a las norteamericanas

Acercando la lente al señalado encarecimiento de los costos de 
producción de El Salvador respecto a los norteamericanos que mostraban los ICLUR, se pueden señalar tres aspectos:

-En primer lugar, la evolución desfavorable o pobre para El Salvador con Estados Unidos mostrada por ambos ICLUR, tiene entre uno de sus principales factores a los pobres resultados que ha tenido en el largo plazo la productividad manufacturera salvadoreña respecto a la norteamericana, lo cual se visualiza en el gráfico $2 \mathrm{C} .{ }^{25}$

Hay que señalar que un elemento fundamental para el incremento de la fuerza productiva del trabajo en el ámbito del capitalismo, ${ }^{26}$ y en consecuencia para la competitividad de costos de los capitales y sus empresas, es el mejoramiento de la tecnología de producción ligado a la acumulación de capital, la cual en tanto supere a las mejoras de los adversarios, permitiría reducir relativamente los costos unitarios de producción y posicionarse mejor. ${ }^{27}$

Los datos del cuadro 2c aportan evidencia sobre que el sector capitalista manufacturero de El Salvador no ha tenido un crecimiento sostenido de su productividad por encima de lo experimentado por sus competidores norteamericanos, elemento grave si se tiene en cuenta que estos últimos muy seguramente poseían una ventaja de partida considerable sobre los primeros. ${ }^{28}$
Esto muestra por sí mismo la pobre capacidad competitiva global de las empresas manufactureras salvadoreñas, y el ahondamiento de su rezago general respecto a las del Estados Unidos, algo grave si se considera la profundización de la apertura comercial que ha ocurrido con el Tratado de Libre Comercio entre Centroamérica y Estados Unidos (RD-CAFTA). ${ }^{29}$ Según datos de Góchez (2008b), esta evolución rezagada de la productividad de El Salvador respecto a Estados Unidos, no es algo nuevo, sino que ha sido la constante durante todo el período de liberalización (1990-2008).

-En segundo lugar, el incremento menor de la productividad de El Salvador respecto a la norteamericana, que tendería a encarecer relativamente los bienes del primero, ha sido atenuado en alguna medida por la erosión o estancamiento de los salarios medios reales salvadoreños —deflactados por el IPC—, como se puede apreciar en el cuadro $2 b$. En ese cuadro se puede apreciar la reducción del indicador de los salarios reales salvadoreños - deflactados por el IPC - respecto al valor inicial, que contrasta con el crecimiento de los norteamericanos. Esto evidencia que un elemento central de las estrategias de reducción de costos de las empresas y del gobierno salvadoreño, en el contexto de la liberalización comercial, ha sido disminuir la capacidad de compra de los salarios dados los pobres resultados de la productividad. 
Hay que señalar que la reducción de salarios como estrategia competitiva, si bien permite reducir costos en lo inmediato, es una vía espuria, pues la misma tiene consecuencias sumamente negativas para la reproducción de la fuerza de trabajo (cobertura de las necesidades y calidad de vida), para la misma economía (restricción de la demanda efectiva y reducción aun mayor de mercados de por si pequeños), se enfrenta a limites sociales y políticos —resistencia social y limitaciones legales-, y no garantiza superar a los rivales en el largo plazo cuando estos pueden incrementar lo suficiente su productividad.

Es esta erosión de los salarios reales vistos como capacidad de compra, lo que explica en gran medida que el indicador de los ICLUR2, que los utiliza, se mantenga casi constantes entre inicios del 2000 y fines del 2009, sin mostrar el encarecimiento relativo de los costos de producción de la manufactura salvadoreña respecto a los norteamericanos, que sí muestra el indicador de los ICLUR1, que utiliza salarios reales deflactados por el IPM. Los datos de los salarios reales — calculados con el IPC - muestran que en el contexto de liberalización, las empresas manufactureras del país han acudido en forma importante a la erosión o estancamiento de la capacidad de compra de los salarios, y no a los incrementos de productividad, para hacer frente a la competencia de sus rivales. ${ }^{30}$
- Un tercer elemento consiste en que la estrategia espuria de competitividad por la erosión de los salarios reales, muestra ya signos de encontrar su límite social e incluso de haber sido insuficiente para que las empresas salvadoreñas puedan reducir sus costos de producción unitarios. $^{31}$ Esto se puede apreciar más claro en el gráfico $2 b$, ya que se puede visualizar que a pesar que los salarios reales considerados como capacidad de compra - deflactados por el IPC - han caído respecto al inicio de 1999, cuando se estiman como costo de producción, ${ }^{32}$ es decir deflactándolos por los precios a los mayoristas (IPM) que enfrentan las empresas, lo que se visualiza es que han tenido una tendencia levemente a crecer para varios períodos entre 1999-2009. ${ }^{33}$

Es decir, que la estrategia de erosión de la capacidad de compra de los salarios que han utilizado las empresas de El Salvador durante los últimos veinte años, ya no es suficiente para que estos se reduzcan suficientemente respecto al precio del resto de sus insumos o de los bienes producidos. Es en gran parte debido a esto último, que los ICLUR1 utilizando los salarios reales deflactados por el IPM, muestra un encarecimiento relativo de los costos de producción salvadoreños respecto a los norteamericanos, mientras que los ICLUR2 utilizando los salarios reales deflactados por el IPC muestran una relativa constancia de los costos alrededor 
del valor inicial o incluso un cierto abaratamiento. ${ }^{34}$

Un aspecto complementario al anterior análisis de costos, es explorar indicadores sobre la diversificación/concentración de las exportaciones e importaciones, para verificar que tan extendida ha sido la desventaja competitiva en el universo del comercio de bienes. Sobre tales aspectos se presentan dos cuadros a continuación, 3a y $3 \mathrm{~b}$, para el caso de las relaciones El Salvador y Estados Unidos en el período 2005-2009.

\section{Gráfico 3a}

Número mensual de partidas arancelarias (ocho dígitos) de los flujos comerciales no maquileros de El Salvador (ES) a Estados Unidos (USA)

Nota: se utilizan las partidas a 8 dígitos del Sistema Arancelario Centroamericano (SAC). Según tabla proporcionada por el Banco Central de Reserva (BCR) sobre el SAC ocho dígitos se ha considerado que existen alrededor de 6,566 partidas a ocho dígitos.

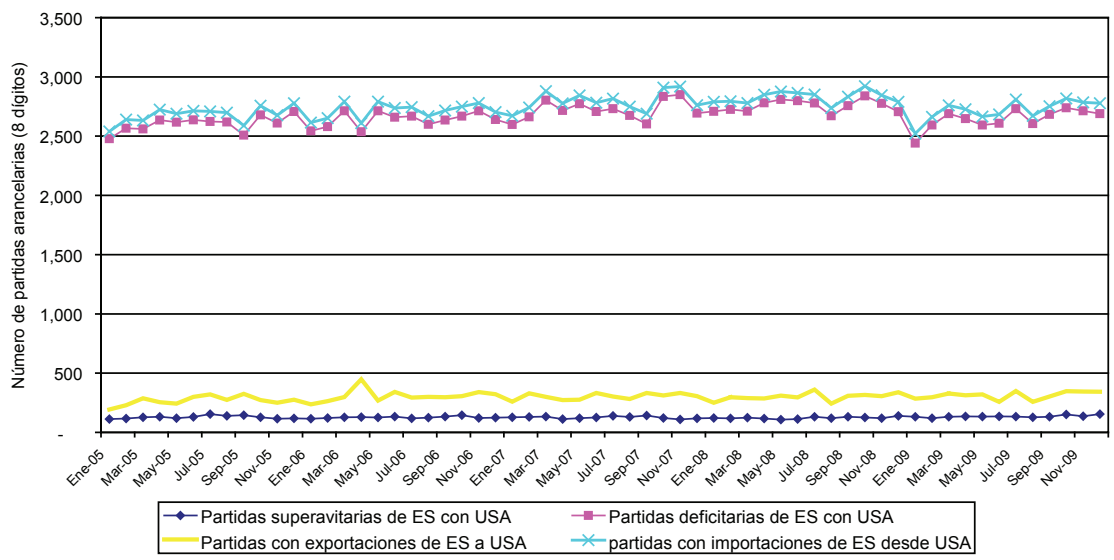


Indicador mensual de concentración (IHHn) de partidas arancelarias (8 dígitos) de los flujos comerciales no maquileros de El Salvador (ES) con Estados Unidos (USA). Media móvil: tres meses

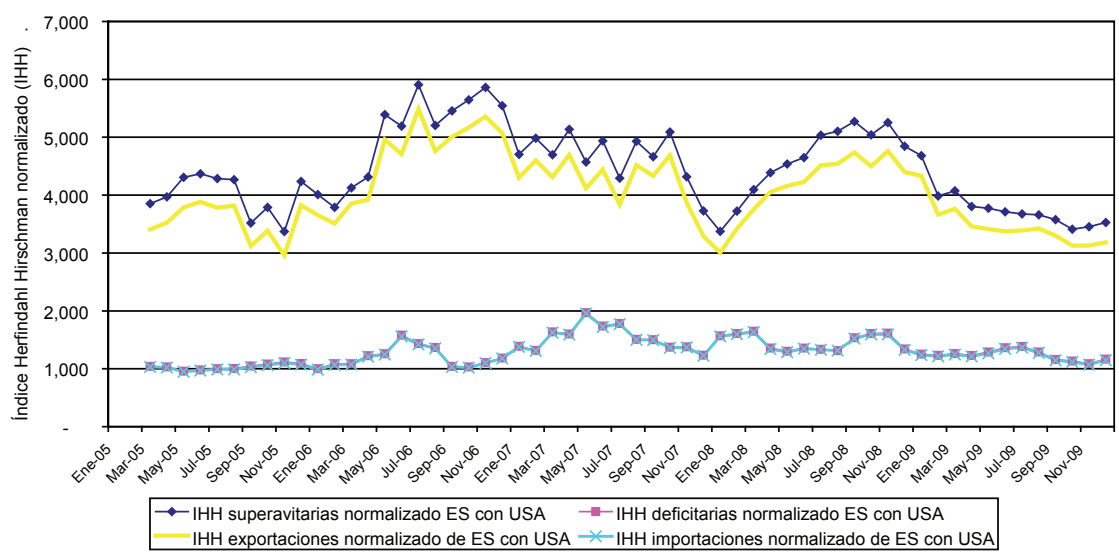

Nota: El IHH es el indicador de concentración Índice Herfindahl-Hirschman (IHH) normalizado, que va de un valor de 0 (mínima concentración) hasta uno máximo de 10,000 (máxima concentración); se normalizó el IHH considerando que existen 6,566 partidas a 8 dígitos Ver anexo 2 para mayor información sobre su estimación.

Fuente: Elaboración propia, a partir de datos del comercio exterior del BCR disponibles en línea en http://www.bcr.gob.sv . [Consultado en febrero de 2010]

En el gráfico 3a se puede apreciar que entre 2005-2009 es considerablemente mayor el número de partidas arancelarias que El Salvador importa y en las cuales es deficitario con Estados Unidos -en promedio entre dos mil setecientas cincuenta (2750) y dos mil seiscientos setenta (2670) respectivamente- frente a las que éste país exporta o en las cuales posee un saldo positivo -en promedio entre trescientas (300) y ciento treinta (130) respectivamente- con dicha nación norteamericana. Estos datos reflejan la poca variedad de productos que el país exporta o que le generan divisas en términos netos $y$, por el contrario, la amplia gama de bienes que el país importa y le generan salidas netas de divisas en su comercio con Estados Unidos.

El gráfico 3b, de manera complementaria, presenta el índice Herfindahl-Hirschman, ${ }^{35}$ indicador de concentración, que muestra valores muy altos de concentración en las partidas exportadoras y superavitarias, y bajos en las importadoras y deficitarias con Estados Unidos. Estos resultados muestran, pues, 
que no sólo son pocos bienes lo que se exportan o generan saldos netos positivos, sino que esos flujos se encuentran muy concentrados en pocos de ellos, mientras que por el otro lado los bienes importadores y deficitarios, son muchos y sus flujos se encuentran bastante distribuidos en todos ellos.

En resumen, el creciente déficit comercial y la apreciación sostenida del tipo de cambio real salvadoreño, que se han dado con la liberalización comercial y que tiene su origen en aspectos estructurales como la desventaja competitiva del sector manufacturero salvadoreño, no dan muestras de revertirse. Más bien, los datos aportados muestran que las estrategias del sector manufacturero sigue descansando en prácticas espurias como la reducción de los salarios reales y una dinámica pobre de la productividad, que sin embargo no le permiten una reduc- ción sostenida de sus costos frente a sus competidores de Estados Unidos. Los datos de concentración y número de partidas importadas/ exportadas también sugieren que la desventaja competitiva es amplia y diversificada, mientras que existe una oferta exportable poco diversificada y concentrada.

Un esquema de liberalización comercial amplio, con un rezago productivo generalizado y que persiste, como es el caso de El Salvador, resulta difícil suponer que genere resultados sustancialmente diferentes a los observados. Más bien lo que parece descabellado es no considerar lo perjudicial que puede ser tal esquema de liberalización, principalmente para los trabajadores y trabajadoras, en cuanto a que no garantiza la creación ni el mantenimiento de empleos en la cantidad y calidad necesarios para el país.

\section{Financiamiento del desequilibrio de la balanza comercial}

La situación de déficit comercial creciente del país no podría haber sido posible sin la existencia de flujos monetarios que pudieran financiar tal brecha. Precisamente, como se señaló lo propio del funcionamiento de las economías capitalistas es la existencia o generación de flujos financieros y de capital, que permiten financiar, e incluso aumentar lo desequilibrios comerciales, lo cual no está exento de problemas futuros por el endeudamiento creciente que pueden generar. ${ }^{36}$ Excepcionalmente algunas economías pueden tener donaciones o flujos de remesas, que tienen la "ventaja" de no generar un proceso de endeudamiento.

Precisamente para el caso particular de El Salvador, en las últimas dos décadas, han sido fundamentalmente los flujos de remesas los que han permitido financiar la brecha comercial creciente. Dada 
la importancia de las remesas para el financiamiento de los desequilibrios comerciales del país, conviene analizar en primer lugar estos flujos y su evolución en los últimos años. En segundo lugar, se analizará la balanza de pagos, comparando las remesas con otros flujos de la misma y su importancia en el financiamiento de los desequilibrios comerciales y de cuenta corriente.

\subsection{Remesas familiares}

La lectura de las remesas se suele detallar como una simple transferencia de ingresos de un país a otro. Particularmente, en el caso de El Salvador, se trata de transferencias de ingresos provenientes de Estados Unidos. Sin embargo, poco se detalla sobre el verdadero móvil de éstas. Más que una simple cesión, las remesas representan transferencias de servicio de factores de producción. Específicamente, se trata de una fuerza de trabajo que, al no poder ser absorbida por el mercado laboral, se ve obligada a emigrar y posteriormente envía transferencias monetarias en apoyo a sus parientes en el país. En este sentido, se puede problematizar y poner al debate la relación costo/ beneficio de las remesas para el caso salvadoreño.

Por el lado del costo, aspecto muy poco abordado en los análisis relacionados con la remesas, se puede enfatizar desde la enorme fuga del principal factor de producción, la fuerza de trabajo, ${ }^{37}$ hasta la desintegración familiar, el tráfico de personas, la peligrosidad de la ruta del destino, entre otros aspectos.

Con esto último, no se pretende menospreciar, ni mucho menos, el enorme impacto de las remesas en el desarrollo humano de este país, que va desde la mitigación de la pobreza, dado que ha facilitado la cobertura de servicios básicos, vivienda, educación, vivienda, empleo, etc., hasta el hecho de convertirse en un referente para el análisis macroeconómico.

Después de las consideraciones anteriores, resulta pertinente dar un vistazo al desenvolvimiento de las remesas, como se detalla en las gráfico $4 \mathrm{a}$ y $4 \mathrm{~b}$ siguiente. En el gráfico 4a es posible visualizar un importante crecimiento de las remesas para el período 1999 hasta mediados del 2008. 
Gráfico 4a

Ingresos mensuales por remesas

medias móviles doce términos

(De diciembre de 1999 a diciembre de 2010)

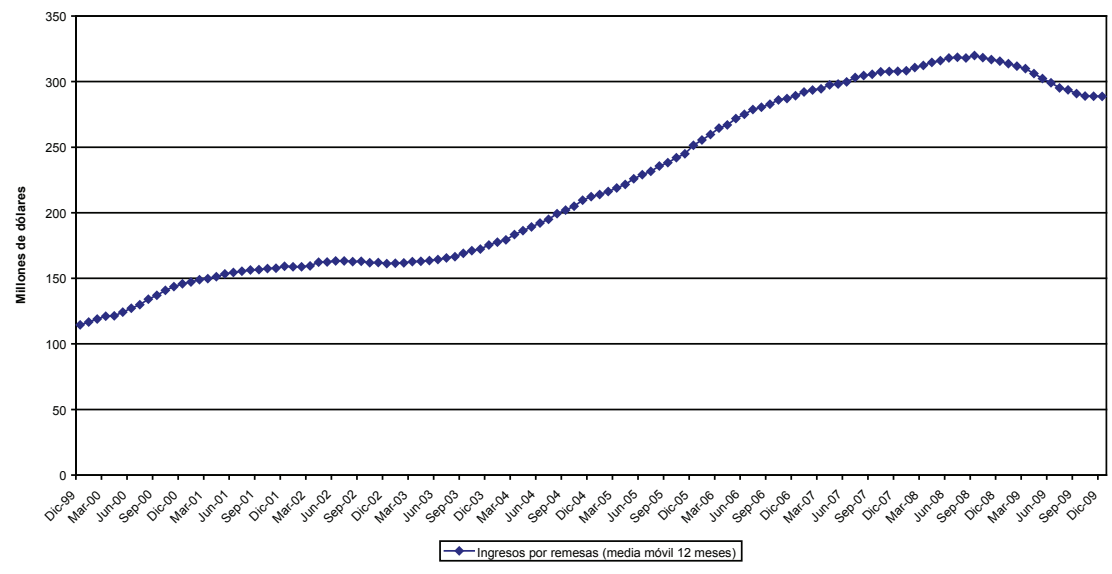

Gráfico 4b

Ingresos mensuales por remesas

2008-2009

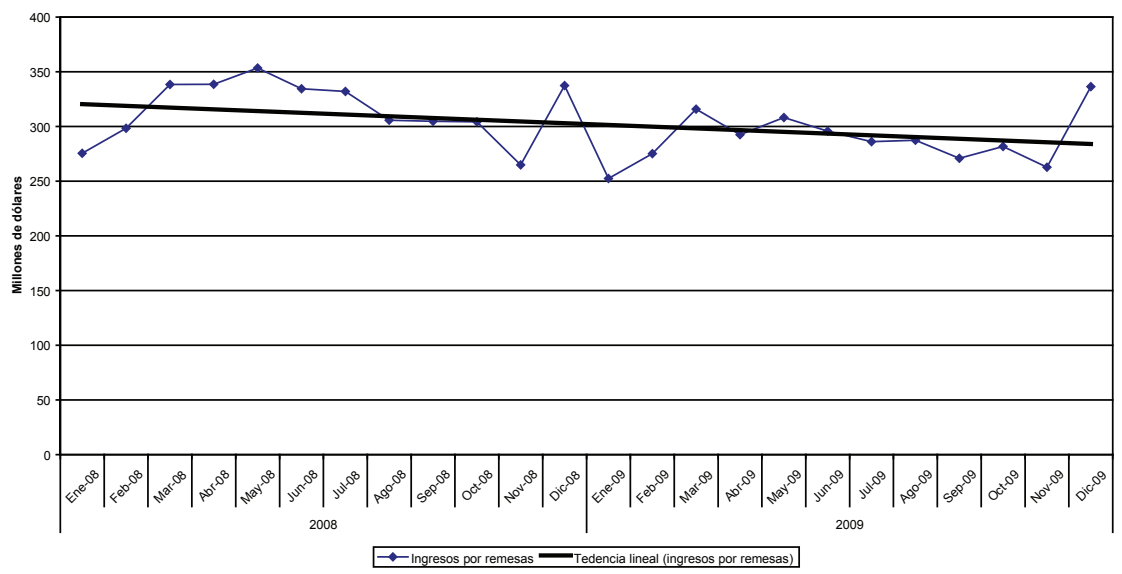

Fuente: Elaboración propia, a partir de datos del BCR disponibles en línea en http://www.bcr. gob.sv . [Consultado en febrero de 2010] 
En los gráficos $4 a$ y $4 b$, puede apreciarse que la afluencia de las remesas familiares hacia El Salvador ha mostrado en los últimos meses una tendencia hacia la baja. Este comportamiento se explica de alguna manera por la crisis en Estados Unidos, cuyas principales repercusiones se manifiestan en el mercado laboral de ese país, sobre todo en los segmentos de trabajadores de poca calificación en su fuerza de trabajo, en la mayoría hispanos.

Por otro lado, es preciso detaIlar la brecha que han contribuido a cerrar las remesas familiares en cuanto a las importaciones, lo cual se detalla en el siguiente gráfico:

\section{Gráfico 5}

\section{Cobertura de remesas familiares de diferentes clases de importaciones}

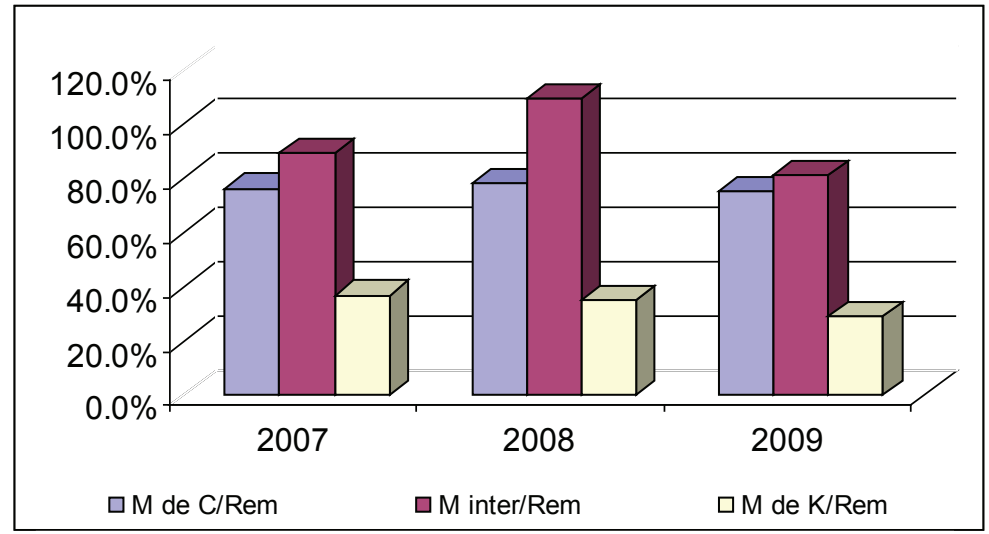

Nota: $\mathrm{M}$ de $\mathrm{C}=$ importaciones de bienes de consumo, $\mathrm{M}$ inter= importaciones de bienes intermedios, $\mathrm{M}$ de $\mathrm{K}=$ importaciones de bienes de capital y Rem= remesas familiares.

Este gráfico denota la capacidad de cobertura que tienes las remesas familiares para financiar las importaciones. En este sentido, el 100\% representa el ingreso total proveniente de las remesas familiares, y cada cociente representa el porcentaje de las respectivas importaciones de los ingresos de remesas.

Fuente: Elaboración propia, a partir de datos del BCR disponibles en línea en http://www.bcr. gob.sv. [Consultado en febrero de 2010]

Del gráfico 5, destacan dos aspectos: el primero es la capacidad de las remesas familiares para financiar gran parte de las importaciones en su conjunto, resaltando la cobertura total tanto en los bienes de consumo, como los de capital, y en menor grado los bienes intermedios ${ }^{38}$, dado que estos últimos representan casi la totalidad del ingreso proveniente remesas familiares. 
El segundo aspecto del gráfico 5 es el grado de importancia que tienen los bienes importados en la dinámica del comercio internacional que tiene el país. De esta manera, se observa que son las importaciones en bienes de capital, los que registran valores menores, que de alguna manera indica que las importaciones no están cumpliendo con la función de aportar a la formación bruta de capital, transferencia de tecnología e inversión, entre otros aspectos. A su vez, también se destaca que la dinámica comercial establece la priorización de las importaciones de bienes de consumo, que en su mayoría representan bienes no duraderos sobre todo alimentos y en los bienes intermedios.

\subsection{Balanza de pagos}

Luego de apreciar la importancia de las remesas, conviene analizar las remesas junto con otros flujos, en el marco de la balanza de pagos. Estos datos son presentados en el gráfico 6 en donde se puede apreciar que en El Salvador los flujos de remesas y el incremento de pasivos con el exterior - endeudamiento con el exterior en sentido amplio- han permitido cubrir el déficit comercial de bienes y servicios, así como la creciente salida de divisas por concepto de pago de rentas de inversión (intereses y dividendos).

En el Cuadro 6, se destacan algunos saldos parciales de la balanza de pagos como cocientes del producto interno bruto (PIB), indicando su signo si son superavitarios (signo positivo) o deficitarios (negativo). En primer lugar se puede apreciar que la balanza de bienes y servicios ha sido deficitaria durante todo el período, lo cual se ha reflejado en que dicho saldo ha representado entre el $-13 \%$ y $-25 \%$ del PIB, teniendo un pico en 2008, año en que alcanzó el $-25 \%$ del Producto Interno Bruto (PIB). ${ }^{39}$ En segundo lugar, si a la balanza de bienes y servicios se le agregan las persistentes salidas de divisas por concepto de rentas de inversión de los extranjeros -intereses y dividendos-, que se han mantenido en un nivel promedio del $-3 \%$ del PIB, el saldo se hace aun más deficitario, estando entre el $-17 \%$ y $-30 \%$ del PIB, llegando a un pico de casi el $-30 \%$ del PIB entre 2007 y 2008.

En tercer lugar, hay que destacar que han sido precisamente las remesas de los trabajadores, las que permiten reducir considerablemente la brecha negativa del comercio de bienes, servicios y rentas de inversión. Al agregar las remesas, al déficit comercial de bienes, servicios y rentas de inversión, el resultado es un saldo de menor magnitud, si bien aun negativo, que se ha mantenido entre los valores del $-5 \%$ y $-11 \%$ del PIB. En cuarto lugar, si bien el endeudamiento aporta una menor cantidad de divisas que las remesas y genera obligaciones futuras de sentido inverso, ha tenido un 
peso nada despreciable que cubrir la salida de divisas. Esto último se aprecia cuando se le agregan a la balanza del comercio de bienes, servicios, renta de inversión y remesas, las entradas netas de divisas provenientes del aumento neto de pasivos con el exterior -endeudamiento-, ya que el saldo ha sido positivo para muchos períodoscon máximos cercanos al $4 \%$ del PIB.

\section{Gráfico 6}

Agregados de Balanza de Pagos como porcentaje del PIB trimestral Medias móviles: 4 términos

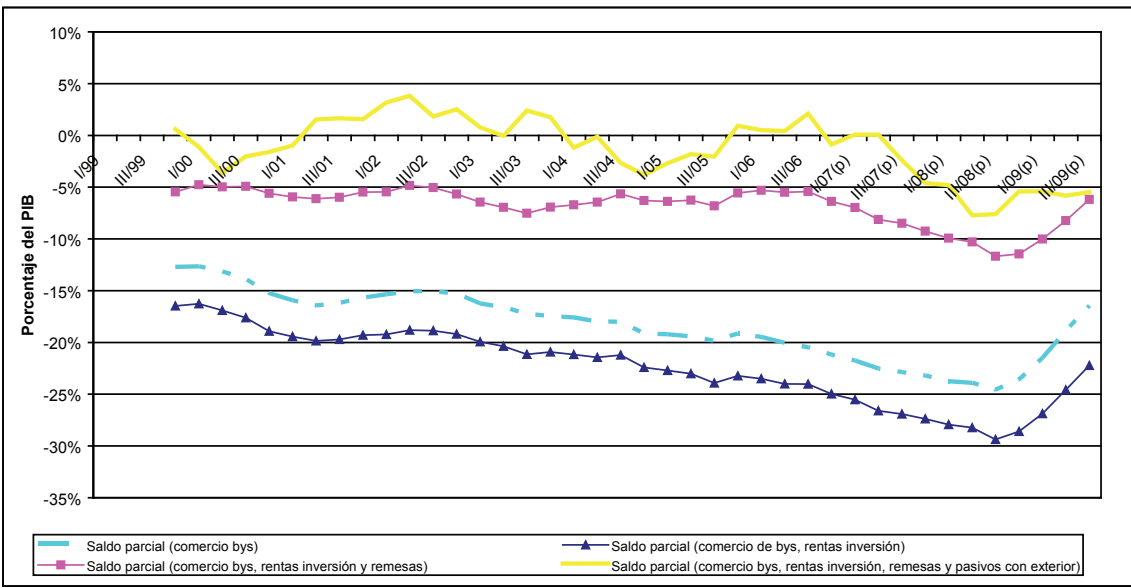

Nota. Se han calculado medias móviles de cuatro términos para suavizar el comportamiento de las series. Los datos del cuadro comprenden hasta el tercer trimestre del 2009. Los datos negativos indican un saldo deficitario de la respectiva cuenta de la balanza de pagos, mientras que los positivos, un saldo superavitario.

Fuente: Elaboración propia, a partir de datos del BCR disponibles en línea en http://www.bcr. gob.sv . [Consultado en febrero de 2010]

Hay que mencionar que el esquema señalado ha tenido tres cambios importantes en los últimos dos años, pues, en primer lugar, ha habido una disminución de la salida de divisas por la reducción del déficit de balanza comercial ya señalado; en segundo lugar, la economía ha visto reducir los flujos y peso de las remesas; y en tercer lugar, el incremento neto de pasivos con el exterior se ha vuelto negativo, lo que significa que para los últimos trimestres hay salidas netas de divisas por la reducción neta de pasivos con el exterior (pagos de compromisos), lo cual ha llevado a que la brecha negativa del país por 
el comercio de bienes, servicios, rentas de inversión, remesas y pasivos con el exterior, se mantenga entre el $-5 \%$ del PIB, aun y a pesar del menor déficit comercial. Estas tendencias muestran que el mecanismo de financiamiento de los grandes desequilibrios comerciales y de rentas presenta problemas en el marco de la crisis mundial más reciente

En definitiva el déficit comercial salvadoreño ha podido expandirse principalmente porque el país ha tenido ingresos importantes de remesas, y en segundo lugar por el endeudamiento externo de los últimos años. Sin embargo, hay que tener en cuenta que si bien ambos flujos han permitido que este se mantenga, $y$ en esa medida han influido en el mismo, su origen y evolución están fuertemente enraizados en la desventaja competitiva y en los pobres progresos en la competitividad de costos del sector empresarial salvadoreño.

\section{Conclusiones}

Como una reflexión general, hay que señalar que, en los últimos años, con la profundización de la liberalización comercial, principalmente a raíz de la firma de Tratados de Libre Comercio entre Centroamérica y Estados Unidos (RD-CAFTA), el sector manufacturero salvadoreño sigue mostrando pobres logros en mantener un crecimiento alto y sostenido de la productividad del trabajo, y por el contrario muestra su persistencia en competir a través de salarios reales bajos y deprimidos. Tal estrategia espuria va mostrando cada vez más sus límites y sus consecuencias sociales negativas, y no ha permitido superar sistemáticamente la evolución de los costos de la economía norteamericana.

El rezago productivo relativo del sector manufacturero salvadoreño, en el contexto de la liberaliza- ción comercial de los últimos veinte años, es una de las causas estructurales del creciente déficit comercial del país y de la apreciación real con el extranjero. El aparato productivo salvadoreño lejos de aportar relativamente más divisas para financiar las importaciones, ha mostrado una acentuación de su dependencia exterior como lo muestra el hecho que las importaciones de bienes intermedios y de capital representaron en promedio entre 1999-2009 alrededor del $20 \%$ del PIB y $153 \%$ de las exportaciones totales con maquila neta.

El Salvador es, principalmente, gracias a las remesas de los migrantes, el país que ha podido sostener ese esquema de un creciente déficit comercial y, al mismo tiempo, atenuar en cierta medida el ritmo de endeudamiento externo que le hubiera significado financiar tal 
brecha únicamente con préstamos o inversión de cartera. Son también las remesas las que le han permitido sortear o diferir una posible crisis de balanza de pagos o cambiaria, a pesar del abultado peso del déficit de cuenta corriente.

El esquema descrito, sin embargo no deja de ser paradójico, pues resulta que son los flujos de remesas de los emigrantes los que contribuyen sustancialmente a aportar divisas para financiar el déficit del comercio de bienes, servicios y rentas de inversión de la economía salvadoreña, $y$ en cierto sentido $-y$ seguramente muy a pesar suyocontribuyen involuntariamente a mantener tal esquema de la economía salvadoreña. Paradójico, porque las remesas provienen de una población expulsada del país por el funcionamiento del sistema económico, que se vieron castigados por condiciones laborales precarias mientras estuvieron en el país, que se ven obligados a apoyar económicamente a sus familiares que permanecen en el país en malas condiciones laborales, y que para colmo es una población que es perseguida en su esfuerzo de migrar por las leyes de los países de origen, destino y tránsito.

Para revertir la situación de rezago del sector manufacturero y exportador salvadoreño no bastan las buenas voluntades o el espíritu emprendedor de algunos cuantos, sino que requeriría una rápida transformación estructural de la matriz productiva del país capaz de superar sostenidamente a sus competidores para mejorar el desempeño comercial y económico, dado el esquema actual de liberalización comercial. Esta transformación debería ser rápida a raíz de la profundización de la liberalización comercial que traerán los diferentes tratados de libre comercio que el país ha suscrito y se encuentra suscribiendo. Hay que tener en cuenta que la liberalización comercial y, en especial, los tratados de libre comercio suscritos, no son aspectos neutrales para un aparato productivo y exportador atrasado, sino que, por sus efectos, o por las restricciones de políticas que imponen, pueden socavarlo aun más, profundizando la desestructuración productiva, la dependencia exterior y las economías de enclave -maquilizar el aparato exportador.

Dado el escaso progreso de los últimos años en generar una transformación productiva importante o lo irreal de esperar que la economía capitalista rezagada como la salvadoreña pueda superar sostenidamente a las principales potencias económicas, posiblemente el camino más realista para ésta sea reconsiderar y revertir la liberalización comercial de los últimos veinte años. De manera complementariamente puede ser importante para el país establecer un esquema de acuerdos comerciales que no sean de liberalización comercial, sino que más bien 
reconozcan y de un tratamiento a las amplias asimetrías de las economías y los aparatos productivos.

\section{Bibliografía}

Cabrera, O. (2001). La competencia internacional: factores explicativos de la competitividad industrial en los países del mercado común centroamericano. Tesis Doctoral. Universidad de Sevilla

Durán Lima, J. E. y M. Álvarez. (2008). Indicadores de comercio exterior y política comercial: mediciones de posición y dinamismo comercial. CEPAL/ Naciones Unidas. Disponible en línea en: http://www.eclac. $\mathrm{cl} /$ comercio/publicaciones/ xml/7/34897/Mediciones_Posicion_Dinamismo_Comercial_ LCW217.pdf [Consultado el20 de julio de 2010]

El Diario de Hoy (2002). "El TLC triplicará las exportaciones, 'Ya estamos negociando': Lacayo". Viernes 18 de enero. Disponible en: http://www.elsalvador. com/noticias/2002/1/18/NEGOCIOS/negoc1.html [Consultado el 5 de marzo de 2010]

Féliz, M. y I. Sorokin (2008), „¿Rigidez estructural del tipo de cambio? El caso de la Argentina a la luz de un enfoque marxista", en Toledo F. y Neffa, J.C. (comp.), Interpretaciones heterodoxas de las crisis económicas en argentina y sus efectos sociales, Editorial Miño y Dávila, Buenos Aires, 368 pp., pp. 283-310, ISBN10: 8496571785. ISBN13: 9788496571785. Disponible en línea en http://issuu.com/ marianfeliz/docs/ih4felizsorokin [Consultado en enero de 2009]

Góchez, R. e I. Álvarez. (2009). La dinámica de la actividad maquiladora en El Salvador 1990-2008. Centro de Estudios y Apoyo Laboral de El Salvador (CEAL).

Góchez, R. (2008a). Elementos marxistas para la crítica de la ortodoxia neoclásica del comercio internacional. Revista Realidad. No. 115. Enero-Marzo 2008. pp. 87-108.

Góchez, R. (2008b). "Evolución de los flujos comerciales de El Salvador (ES)-Estados Unidos (EE.UU.) antes y después del CAFTA", en Red Regional de Monitoreo del CAFTA-DR: EI CAFTA-DR a 2 años de su implementación. Algunas implicaciones Socioeconómica. Segundo Informe de Monitoreo del CAFTA-DR. Publicación colectiva. 2008. pp. 4-23

Gontijo, C. (2000). The Ricardian theory of international trade: a criticism. Texto para discussão. UFMG/CEDEPLAR. Disponible en línea: http://www.cedeplar. 
ufmg.br/pesquisas/td/TD\%20 141.doc [Consultado en enero de 2009]

Guerrero, D. (1995). Competitividad, teoría y política. Barcelona. Ariel.

Martínez, G. (2006). "Factores determinantes de la competitividad de la industria salvadoreña en el marco del TLC con México", en Alternativas para el Desarrollo No. 98 Abril-Mayo 2006. FUNDE. Disponible en línea en sitio web de FUNDE: http://www.funde.org/[Consultado en febrero de 2009]

Marx, C. (1999). El Capital: crítica de la economía política. Tomo I. $3^{a}$. Edición. Fondo de Cultura Económica. México. 5a . Reimpresión (2009).

Ramírez, S. (2010). "MINEC dice hace falta aprovechar el CAFTA". La Prensa Gráfica. 27 de Febrero de 2010. Disponible en: http://www.laprensagrafica. com/economia/nacional/96695minec-dice-hace-falta-aprovechar-el-cafta.html [Consultado el 5 de marzo de 2010]

Rivera Campos, R. (2000). La economía salvadoreña al final del siglo: Desafíos para el futuro. San Salvador. FLACSO.

Ruiz-Nápoles, P. (2001) "Exchange rate and competitiveness", en
Puchet, M. y Punzo, L. Mexico Beyond NAFTA. Perspectives for the european debate. London, Routledge. pp. 78-101

Salgado, C. M. (2009). "La liberalización comercial en El Salvador: impactos en el nivel de empleo formal y salarios reales". Revista Realidad. No. 120. Abril-Junio 2009. pp. 321-356.

Sarich, J. (2006). "What do we know about the real exchange rate? A classical cost of production story". Review of Political Economy, volumen 18, número 4, 469-496, Octubre de 2006, pp. $469-496$

Segovia, A. (2002). Transformación estructural y reforma económica en El Salvador. Guatemala. F\&G Editores.

Shaikh, A. (2000). "Los tipos de cambio reales y los movimientos internacionales de capital", en Guerrero, D. (ed). Macroeconomía y Crisis Mundial. Madrid. Editorial Trotta. Versión en inglés disponible en web de Anwar Shaikh: http://homepage.newschool.edu/ AShaikh/ [Consultado en enero de 2009]

Shaikh, A. y R. Antonopoulos. (1998). Explaining long term exchange rate behavior in the United Stated and Japan. New York. Working Paper No. 250. The Jerome Levy Economic 
Institute of Bard College. Disponible en línea en Levy Institute: http://www.levy.org/vauth. aspx?auth=246 [Consultado en enero de 2009]

Shaikh, A. (1991a). Valor, acumulación y crisis. Ensayos de economía política. Bogotá. Tercer Mundo Editores.
Shaikh, A. (1991b). Competition and Exchange Rates: Theory and Empirical Evidence. New York. New School for Social Research. Proporcionado por correo electrónico por el autor.

UNCTAD (2006). Handbook of Statistics. United Nations Publications Disponible en línea en www. unctad.org/statistics/handbook [Consultado en enero de 2008]

\section{Anexo 1 \\ Sobre el cálculo de los costos laborales unitarios reales}

Para los costos unitarios laborales manufactureros de El Salvador (CLUR ES) se utilizaron los siguientes datos:

- La productividad manufacturera (Iproductividad ES) se obtuvo del cociente del índice de volumen de la actividad económica de la manufactura (IVAEM) entre el índice de cotizantes de la manufactura del Instituto Salvadoreño del Seguro Social (ISSS);

1. Los datos mensuales del IVAE de la manufactura (IVAEM) corresponden al Banco Central de Reserva (BCR) disponibles en línea en www.bcr.gob.sv

2. Los datos mensuales del número de cotizantes de la manufactura son proporcionados regularmente por el Instituto Salvadoreño del
Seguro Social (ISSS).

- El índice de salarios medios reales por trabajado se obtuvo del cociente del índice de los salarios medios mensuales nominales de los cotizantes de la manufactura del Instituto Salvadoreño del Seguro Social (ISSS) entre los índices de precios al consumidor (IPC) -el IWmeR (IPC)- y alternativamente se uso el índice de precios al por mayor (IPM) -el IWmeR (IPM);

1. Los datos mensuales de los salarios medios mensuales de los cotizantes de la manufactura son proporcionados regularmente por el Instituto Salvadoreño del Seguro Social (ISSS).

2. Los datos mensuales del índice de precios al consumidor (IPC) corresponden 
al Banco Central de Reserva disponibles en línea en www.bcr.gob.sv

Los datos del índice de precios al por mayor corresponden a las estadísticas financieras internacionales del Fondo Monetario Internacional disponibles en línea en http://www. imfstatistics.org

Para los costos unitarios laborales manufacturero de Estados Unidos (CLUR USA) se utilizaron los siguientes datos:

- La productividad manufacturera (Iproductividad USA) se obtuvo del cociente del índice de producto manufacturero entre el índice de empleados de la manufactura;

1. Los datos trimestrales del índice de producto y de empleados, ambos de la manufactura corresponden al Bureau of Labor Statistics (BLS) disponibles en línea en www.bls.gov

- El índice de salarios medios reales por trabajador se obtuvo del cociente del índice de los salarios medios mensuales nominales de los cotizantes de la manufactura entre los índices de precios al consumidor (IPC) -IWmeR USA (IPC). Alternativamente se usó el índice de precios al productor (IPP), -IWmeR (IPM)-;

1. Los datos trimestrales del índice de salarios medios nominales por trabajador de la manufactura fueron obtenidos del cociente de los índices de masa salarial (compensation) y de empleados (employment), de la manufactura. Estas series corresponden al Bureau of Labor Statistics (Oficina de Estadísticas Laborales, BLS, por sus siglas en inglés), disponibles en línea en: www.bls.gov

2. Los datos trimestrales del índice de precios al consumidor (IPC "all items") y los del de precios al productor (IPP "all commodities") corresponden al BLS, disponibles en línea en: www.bls.gov 


\section{Anexo 2 \\ Sobre el cálculo del Índice \\ Herfindahl-Hirschman normalizado (IHHn)}

El IHHn es el índice Herfindahl-Hirschman normalizado, que es un indicador de concentración que oscila entre 0 (mínima concentración) y 10,000 (máxima concentración). El IHHn se ha estimado con alguna variante al de UNCTAD (2006: 204), y se estimó como:

$$
I H H n=10000 * \frac{\sqrt[2]{I H H}-\sqrt[2]{\frac{1}{n}}}{1-\sqrt[2]{\frac{1}{n}}}
$$

En donde,

n es el número partidas a ocho dígitos del SAC, que se ha tomado como 6,566 en este caso;

IHH es el índice Herfindahl-Hirschman sin normalizar, que se estima a su vez como la suma de los cuadrados de las participaciones de cada partida en el respectivo total del comercio, es decir:

$$
I H H=\sum_{i=1}^{n} p_{i}^{2}
$$

En donde,

pi es la participación del flujo de cada partida i en el total del respectivo flujo del comercio i, subíndice que indica el número de la partida.

Se han calculado cuatro diferentes IHH para los flujos por partidas arancelarias a ocho dígitos del sistema armonizado para cada uno de los flujos de comercio: exportaciones, importaciones, saldos superavitarios y saldos deficitarios. 
Anexo 3

Gráfica A1

Productividad del trabajo en la manufactura total, maquilera y no maquilera (en dólares constantes de 1990/trabajador)

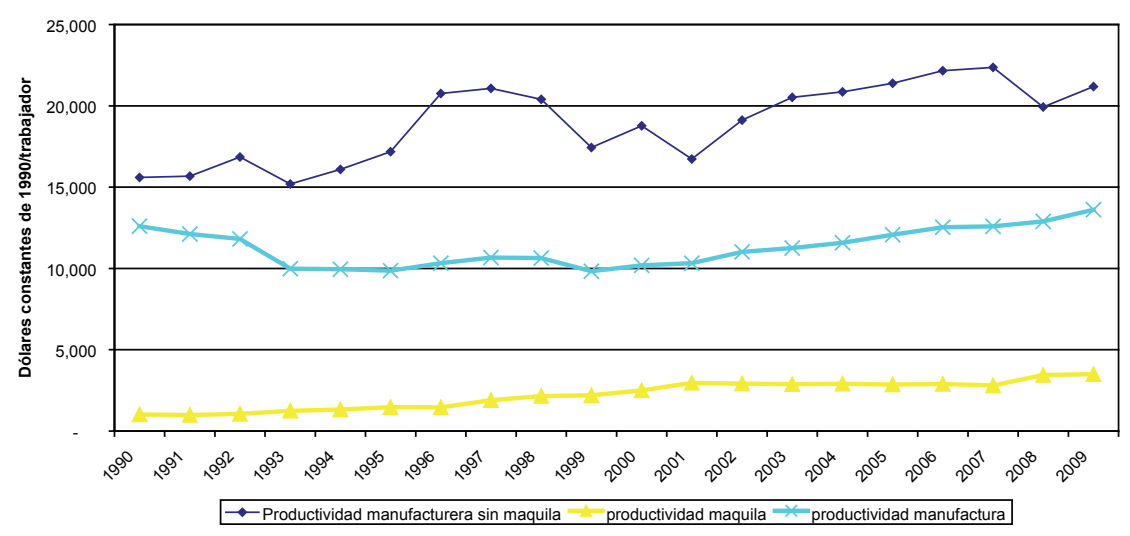

Gráfica A2

Cotizantes de la manufactura no maquilera y de la maquila

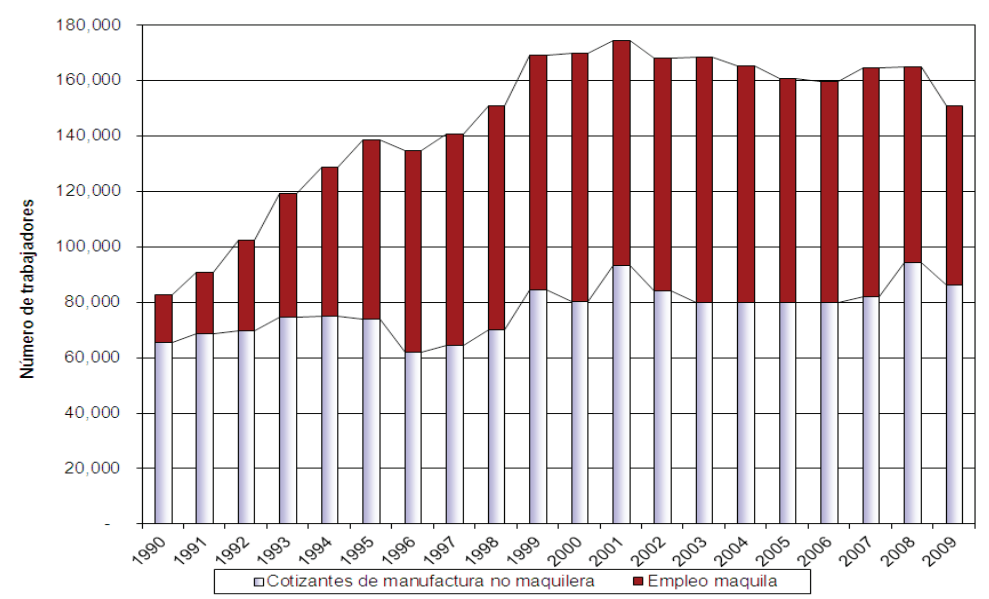

Nota: El número de cotizantes de la manufactura no maquilera se calculó tras restar del total de cotizantes del ISSS el empleo de la maquila. Esto supone asumir que todo el empleo de la maquila cotiza al ISSS. 
Fuente: Elaboración propia, a partir de los datos de: Empleo maquila de 2000-2009 que fueron proporcionados a solicitud nuestra por el Ministerio de Economía (MINEC). Para los años previos, los datos provienen del MINEC, tomados de Góchez et al. (2009). Los datos de los cotizantes manufactureros totales del Instituto del Seguro Social (ISSS), los del producto manufacturero y maquilero del Banco Central de Reserva (BCR) están disponibles en línea en http:// www.bcr.gob.sv . [Consultado en febrero de 2010]

\section{Gráfica A3}

Costos laborales unitarios reales relativos de El Salvador — deflactado por IPM - con Estados Unidos — deflactados por IPP-

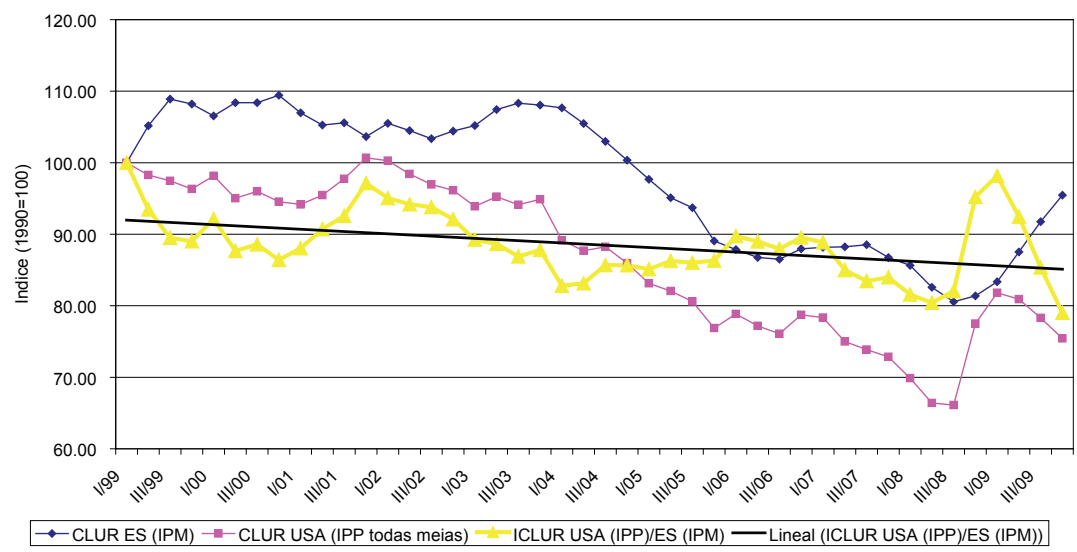

\section{Gráfica A4}

Costos laborales unitarios reales relativos de El Salvador - deflactado por IPC - con Estados Unidos — deflactados por IPC-

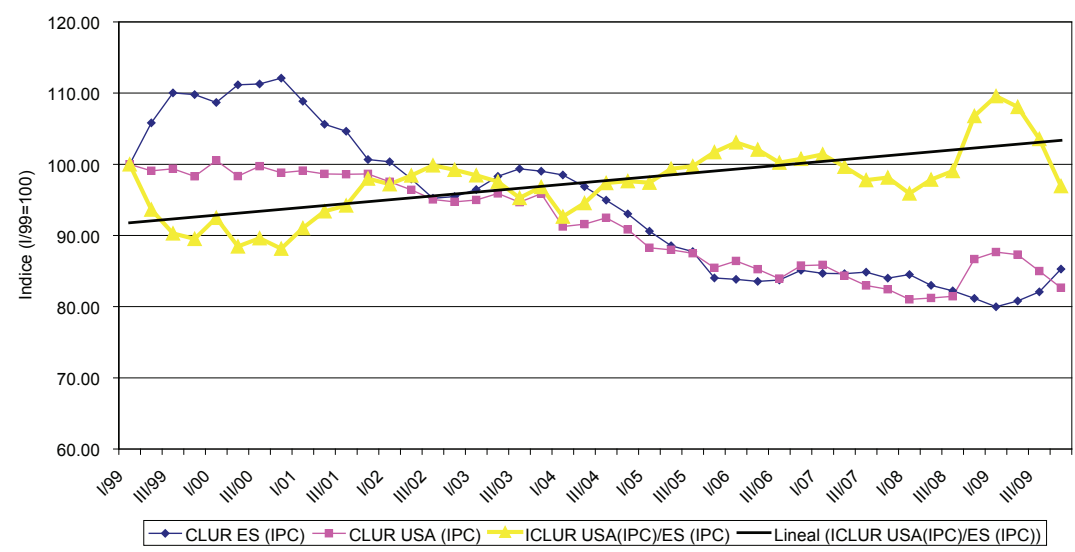

Fuente: Sobre el cálculo de los datos y las fuentes de información, ver anexo 1. 
Gráfica A5

Índice de tipo de cambio real entre El Salvador y Estados Unidos

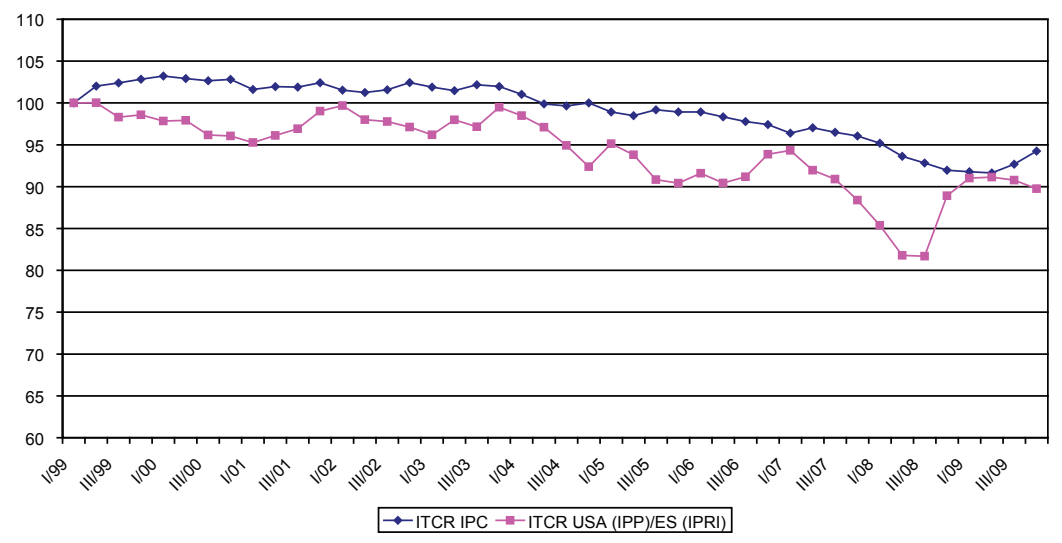

Nota: El ITCR IPC se ha obtenido usando el índice de precios al consumidor de Estados Unidos y El Salvador; el ITCR USA (IPP)/ES(IPRI) se ha obtenido utilizando el índice de precios al productor (IPP manufactureros) de Estados Unidos y el índice de precios industriales de El Salvador. Fuente: Elaboración propia, a partir dedatos del BCR disponibles en línea en http://www.bcr. gob.sv y al Bureau of Labor Statistics (BLS) disponibles en línea en www.bls.gov . [Consultado ens febrero 2010]

Gráfica A6

Índices de Costos Laborales Unitarios Reales Relativos Manufactureros (ICLUR) y tipo de cambio real entre Estados Unidos y El Salvador $(\mathbf{1 9 9 0}=\mathbf{1 0 0})$

1960-2007

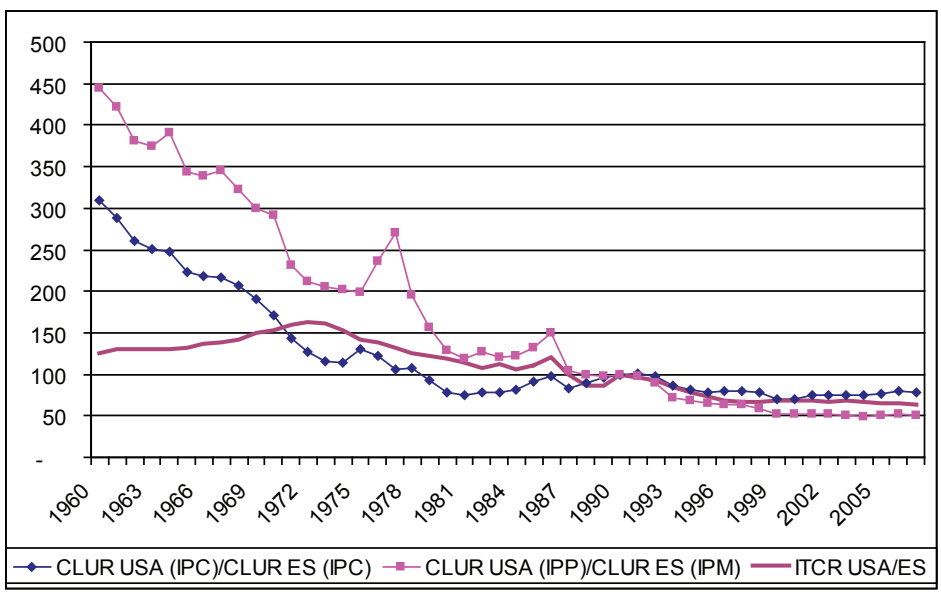




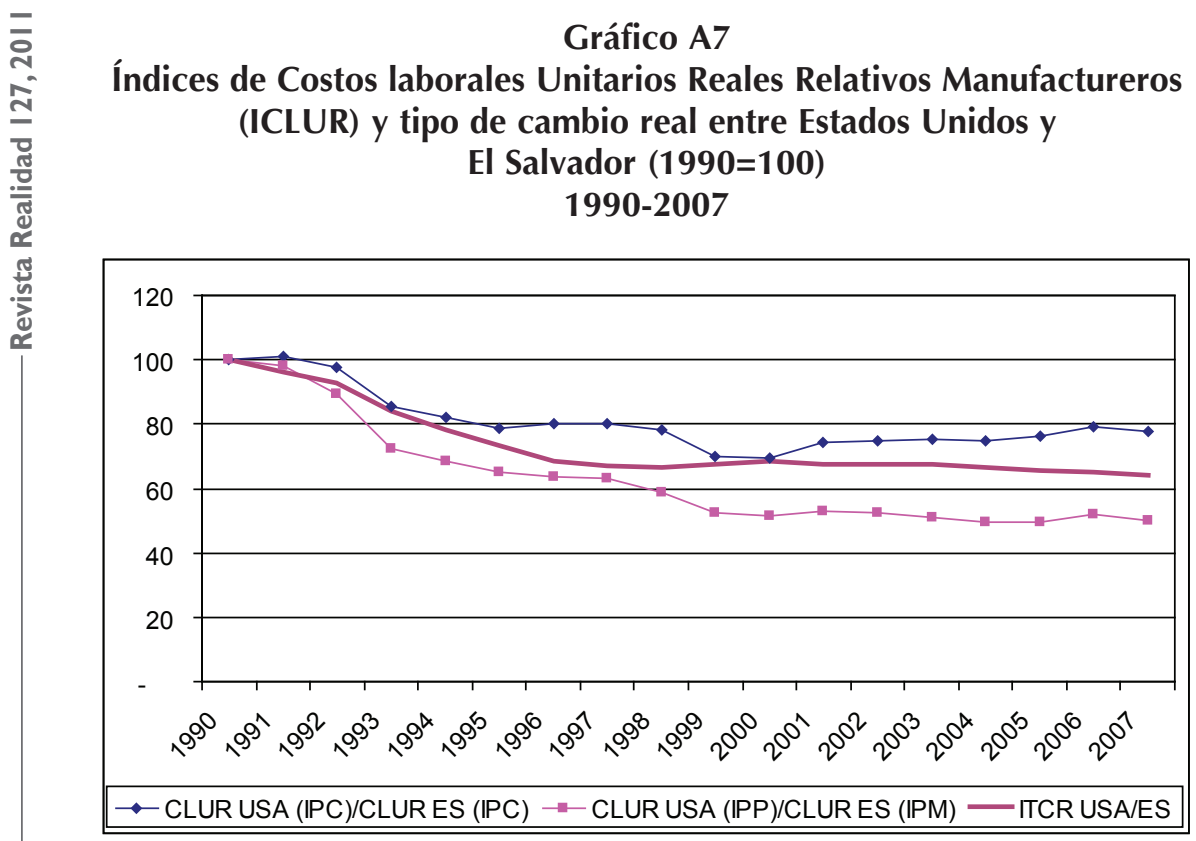

Fuente: Elaboración propia, basada en Góchez, R. (2008b).

Notas

1 Se agradecen las observaciones y comentarios para diferentes borradores del trabajo de los compañeros del Departamento de Economía, Gerardo Olano, Saira Barrera, Marielos García, Aquiles Montoya y Lilian Vega. Sin embargo, la responsabilidad por los errores que persistan y las opiniones vertidas en el trabajo son de los autores.

2 Para diferentes perspectivas sobre el tema de la apreciación cambiaria en El Salvador, ver Rivera Campos (2000: 107-108) y Segovia (2002: 116-118). Sobre el tema del déficit comercial de El Salvador con Estados Unidos, ver Góchez (2008b).

La ventaja comparativa supone que los términos de intercambio de equilibrio que surgen con el "libre comercio" son de equilibrio comercial. Para evitar cualquier equívoco, los términos de intercambio o tipo de cambio real se definen igual que al inicio, es decir como el cociente de los precios extranjeros (p), ajustados por el tipo de cambio (e), sobre locales (p), es decir P e/P. Una depreciación, será un aumento del cociente que indicará encarecimiento de bienes extranjeros y una apreciación será una reducción del cociente que significará un encarecimiento de los bienes locales. 
4 Hay que decir que el modelo neoclásico más popular "elimina”, en cierto sentido, la posible existencia de un país "subdesarrollado" frente a otro "avanzado", dado que en dicho modelo, Heckscher-Ohlin-Samuelson (HOS), se asume que las tecnologías para producir cada bien son iguales entre los países involucrados —asume una única función de producción en cada industria - (Shaikh, 1991a: 159). Al asumir esa igualdad tecnológica entre naciones, en cierto sentido está ignorando una diferencia inobjetable entre el llamado mundo desarrollado y subdesarrollado, sea cual sea la definición que se use: las brechas tecnológicas entre sus empresas.

5 La concepción de la ventaja comparativa sobre la existencia de mecanismos automáticos correctores de los desequilibrios comerciales, o ley de costos comparativos, es fundamental para su visión sobre que un país, por muy atrasado que este fuera y a pesar que produjera inicialmente todos sus bienes más caros, siempre se podrá especializar en algunos de ellos. En general, Shaikh (1991a: 184) señala que la teoría de la ventaja comparativa puede echar mano de diferentes variantes modernas de mecanismos monetarios del tipo de la teoría cuantitativa clásica de Ricardo, que traducen los desequilibrios comerciales iniciales en variaciones "adecuadas" de los precios que tienden a equilibrar la balanza comercial: tipos de cambio flexibles que se ajustan al equilibrio comercial, la versión de saldos reales en efectivo de la teoría cuantitativa y la determinación keynesiana de los precios por medio del nivel salarial. Las ganancias del libre comercio que presenta la ventaja comparativa en realidad están sustentados en esa concepción de mecanismos que tienden a alcanzar el equilibrio comercial. Para un mayor desarrollo de la crítica a los mecanismos monetarios subyacentes de la ventaja comparativa ver Shaikh (1991a).

6 Los modelos neoclásicos del tipo de Heckscher-Ohlin-Samuelson (HOS), al plantearse como de trueque no explicitan los mecanismos monetarios autocorrectos de los desequilibrios monetarios. Sin embargo, es importante señalar que los mismos están asentados en la misma base, lo que se puede percibir cuando los mismos señalan que una economía solo podrá importar un monto similar al de sus importaciones, y cuando definen los términos de intercambio de equilibrio de libre comercio como de equilibrio comercial.

$7 \quad$ Las versiones absolutas y relativas de la teoría de la paridad del poder de compra, concluyen que a partir de un cierto equilibrio internacional, que asume un libre comercio más o menos perfecto, los índices de tipo de cambio real entre dos naciones se mantendrán constantes, o para decirlo en lenguaje econométrico, estacionarios, es decir, no se depreciarán ni apreciarán sistemáticamente, en el largo plazo.

El ex Ministro de Economía de El Salvador, Miguel Lacayo, preveía, antes de finalizar las negociaciones, que las exportaciones se triplicarían, se crearían más de 250,000 empleos 


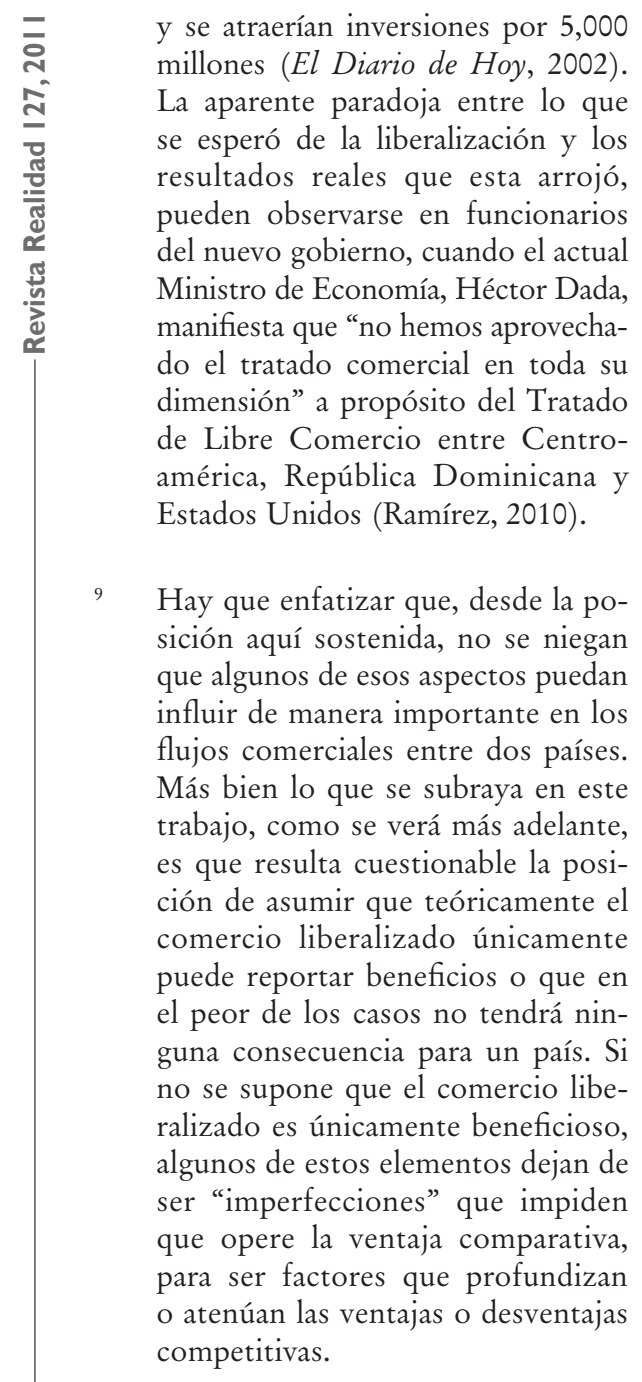

10 No está de más remitir al trabajo de Guerrero (1995), que en su primer capítulo se encarga de señalar múltiples equívocos que cometen los teóricos de las ventajas comparativas al identificar la ventaja absoluta con superioridad de productividad, así como otros respecto a los criterios que corresponderían a cada enfoque.
11 Algunos trabajos que desarrollan el enfoque clásico-marxista, son: a) en el plano teórico: Shaikh (2000; 1991a, 1991b), Guerrero (1995), Gontijo (2000) y Góchez, R. (2008a); b) en el plano teóricoempírico ver Shaikh (1998), Guerrero (1995), Féliz, et al. (2008), Ruiz-Nápoles (2001), Sarich (2006); aplicaciones para El Salvador ver Martínez (2006), Cabrera (2001) y Góchez (2008b).

Es decir, aspectos como buenos puertos, un buen sistema de carreteras, sistemas de transporte eficiente, capacidad comercialización, seguridad pública, bajas tasas de interés, capacidad financiera, fuerza de trabajo calificada, barreras sofisticadas del comercio, etc. pueden potenciar o nulificar la ventaja competitiva de los capitales de un país. Sin embargo, tener una ventaja en esos aspectos sin contar con un aparato productivo o con uno poco diversificado, no necesariamente garantiza que las empresas locales puedan ganarles a sus rivales extranjeros.

13 Las protecciones arancelarias y no arancelarias —cuotas, reglas de origen, normas sanitarias, fitosanitarias y técnicas - pueden atenuar o acentuar tales tendencias, según sea el país que las aplica con mayor rigor $\mathrm{y}$ exigencia.

14 Hay que señalar, que lo que destaca el enfoque clásico-marxista es que los capitales reguladores y su lucha competitiva a nivel mundial — que se refleja en su esfuerzo por reducir sus costos de producción y por moverse hacia las ramas más rentables para aumentar sus ganancias- es lo que 
regula en última instancia los precios mundiales a largo plazo, sobre todo en un entorno comercial más liberalizado. La teoría de los precios de producción constituye la síntesis de las dimensiones intrasectoriales e intersectoriales de la competencia que regularán los tipos de cambio reales. Por lo tanto, el planteamiento teórico reside en que los tipos de cambio reales y términos de intercambio, que son al fin de cuentas precios relativos ajustados por el tipo de cambio, estarán regulados fundamentalmente por tal proceso competitivo, mientras que el comercio y otros mecanismos relacionados a él, más bien son aspectos que pueden influir su tendencia pero no la determinan en el largo plazo. Por capitales reguladores se entienden los capitales predominantes en cada rama de producción, es decir aquellas unidades de capital con la mejor tecnología reproducible a nivel mundial y que poseen por lo tanto los menores costos de reproducción.

La ventaja competitiva clásico-marxista señala que los flujos comerciales deficitarios estarán acompañados por influjos de divisas de diferente tipo, que pueden generar un cierto equilibrio "precario" en la balanza de pagos, y permitir la continuidad de los desequilibrios de la balanza comercial por largos períodos. Son esos flujos los que hacen que no operen los mecanismos autocorrectores que supone la ventaja comparativa.

16 En algunos casos, la exportación a gran escala de algún bien particular, puede permitir a una economía con desventajas generalizadas en el resto de bienes exportar unos montos tales que logren cubrir el déficit de los restantes sectores de dicha economía, tal como puede ser el caso de algunos países petroleros.

Shaikh (2000 y 1991a) plantea, utilizando un esquema matricial, que si bien los precios de producción son la suma de costos los laborales, no laborales y tasa de ganancia, es posible re-expresarlos como costos laborales unitarios reales y ganancias unitarias, ambos verticalmente integradas. Por verticalmente integradas se hace referencia a que los precios se pueden descomponer en costos laborales unitarios y ganancias unitarias, directos más los indirectos. En el planteamiento de este autor se señala que es posible aproximar la tendencia de un cociente de los precios por el ratio de los costos laborales unitarios verticalmente integrados. Sin embargo, en las aplicaciones empíricas de este enfoque, suelen utilizarse como proxy los índices de costos laborales unitarios directos para el caso de series de tiempo, principalmente por problemas de disponibilidad estadística para estimar los verticalmente integrados o alternamente por la ausencia de estadísticas de costos no laborales unitarios. Lo anterior abre la cuestión empírica si los costos no laborales unitarios siguen la trayectoria de los costos laborales unitarios directos en el largo plazo. Sin embargo resulta erróneo atribuir a Shaikh y su enfoque que un capital se impondría a otro si tiene menores costos laborales unitarios directos.

18 Hay que enfatizar que para Shaikh (1991b), los costos de producción 


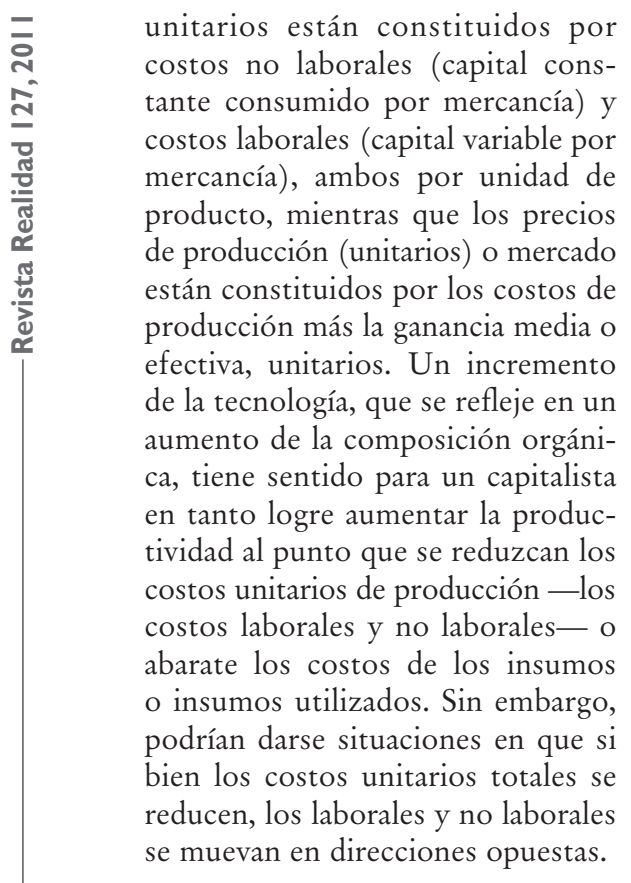

19 La proposición empírica de Shaikh (1991b; 1998), y otros autores inspirados en su planteamiento, es que el índice de tipo de cambio real sigue en el largo plazo la trayectoria del cociente del índice de costos laborales unitarios reales del país local y sus principales socios extranjeros, si bien existen variantes que incluyen otros factores relevantes que pueden ser los flujos de capital, diferenciales de tasas de interés, relación de bienes transables y no transables, ciclo económico. Es decir si el tipo de cambio real se define como el tipo de cambio nominal moneda local/ divisa extranjera (e) por los precios extranjeros (p) entre los precios locales (p), éste vendrá determinado en el largo plazo por el cociente de los costos laborales unitarios reales del país extranjero (CLUR)

y local (CLUR). Es decir: e $\mathrm{p} / \mathrm{p} \approx$ CLUR /CLUR.

20 aspectos estrechamente vinculados: se le presentan como costos para las empresas que los contratan, pero a la vuelta se les presentan como capacidad de compra a las empresas que les venden sus bienes y servicios. En rigor, si los salarios se analizan en su aspecto de costos, los salarios reales deberían estimarse deflactándolos por los precios al productor, mientras que cuando se hacen por su capacidad adquisitiva se deberían deflactar por los precios al consumidor. Sin embargo, por la calidad de los índices existentes y la ausencia de índice de precios al productor en el país, se valoró estimar complementariamente salarios reales con precios al por mayor (salarios como costos) y con precios al consumidor (salarios como capacidad de compra). En todo caso, ambos índices nos dicen información complementaria de la realidad, como se podrá ver en las siguientes páginas. Sobre la metodología y las fuentes de datos de los costos laborales unitarios reales relativos, ver el anexo 1.

Hay que enfatizar que lo mostrado en el gráfico 2 son índices que se construyeron tomando como año base el primer trimestre de 1999, lo cual tiene por objetivo facilitar su presentación. En ese sentido lo que interesa en los gráficos es la trayectoria de dichos índices a crecer o decrecer, y no tanto su valor. Esto quiere decir que en el año base que coinciden los índices de El Salvador y Estados Unidos en el valor de 100, no significa que los valores absolu- 
tos de los costos laborales unitarios hayan sido los mismos.

22 En el gráfico 2 b no se presentan los datos del salario real norteamericano deflactado por el índice de precios al productor (IPP) por claridad del gráfico. Sin embargo, los datos estimados del mismo sugieren una tendencia de los salarios reales a caer a partir del 2004.

En el anexo se presenta el gráfico A5, en el cual se calcula el ITCR utilizando los índices de precios al consumidor (IPC) de cada país y el que utiliza el índice de precios al productor (IPP manufactureros) para Estados Unidos e índice de precios industriales (IPRI) de El Salvador. Ambos indican una apreciación para el período. Sin embargo, la que utiliza los IPC muestra una tendencia menos pronunciada.

24 Para una mayor claridad de los costos laborales unitarios reales utilizando el índice de precios al por mayor (IPM) y al consumidor (IPC), ver gráficos A3 y A4. En dichos gráficos se aprecia que los CLUR de El Salvador utilizando el IPC tienen una caída más pronunciada que los que utilizan el IPM.

25 Para un análisis de largo plazo de la tendencia de los costos laborales unitarios relativos de El Salvador con Estados Unidos, ver Góchez (2008b); para el caso de México, ver Martínez (2006) y para el de varios países centroamericanos, ver Cabrera (2001). En los gráficos A6 y A7 de los anexos se pueden visualizar las tendencias de largo plazo de los ICLUR entre El Salvador y Estados
Unidos, las cuales muestran una tendencia, clara a partir de 1990, hacia el encarecimiento relativo de los costos laborales salvadoreños, que coincide bastante con la apreciación real del tipo de cambio de largo plazo (ITCR).

En el abordaje marxista se considera que los capitalistas tienen la compulsión de mejorar constantemente su tecnología y organización productiva, so pena de perecer frente a sus competidores si se quedan rezagados. Otra razón de lo anterior es procurar ganancias extraordinarias. Esta tendencia de la incesante mejora de la tecnología y organización de la producción se recoge en la teoría marxista en la concepción de un sistema que compulsivamente tiende a un continuo aumento de la composición orgánica del capital que incrementa la fuerza productiva del trabajo. Un incremento de la fuerza productiva del trabajo implica que los costos totales se distribuirán en una mayor cantidad de bienes, lo que implica que se abarate el costo unitario de producción. Sin embargo, el resultado final de este proceso no necesariamente es siempre el aumento de las ganancias ni de su tasa de ganancias.

Los elementos centrales que incrementan la fuerza productiva del trabajo para Marx (1999: 7) son el grado de destreza de los trabajadores, el nivel de progreso de la ciencia y sus aplicaciones, la organización social del proceso de producción, el volumen y eficacia de los medios de producción y las condiciones naturales. Valga señalar que para la concepción marxista, no se hace diferencia de la produc- 


tividad de los "diferentes factores",
y se considera que el trabajo es el
énico productivo porque en rigor es
el único que genera valor, siendo que
la tecnología, organización social del
trabajo, y otros elementos, influyen
en aumentar o reducir la productivi-
dad del trabajo. Es importante aclarar
que la fuerza productiva del trabajo,
desde la concepción marxista, no
proviene únicamente ni fundamental-
mente de características individuales
del trabajador.

Se considera que esa menor dinámica de la productividad salvadoreña respecto a Estados Unidos, desde la perspectiva del trabajo, corresponde tanto a una mejoría débil de la tecnología de producción —esto es, un lento avance del progreso técnico- por parte de la manufactura del país en promedio, como al enorme crecimiento relativo de la fuerza laboral ocupada en industrias intensivas en mano de obra barata y de baja productividad, como la maquila. Sobre este aspecto, ver el anexo 3, en donde se muestra que la productividad manufacturera no maquilera y la maquilera han tenido una tendencia creciente, sin embargo dado el enorme crecimiento en el número de ocupados en la maquila, que tiene una productividad menor a la no maquila, ha hecho que la productividad promedio se mantenga casi sin aumentar (horizontal), sobre todo previo al 2000 . Esa enorme influencia de la maquila en la productividad manufacturera queda más evidenciado en el hecho que a partir del declive de los ocupados de la misma a partir del 2000 se haya experimentado un crecimiento de la productividad de la manufactura total mayor al de 1990-2000. Por ejemplo, entre 1990 y 2000, cuando la maquila aumentó su peso en el empleo manufacturero del $21 \%$ al $53 \%$, la productividad de la manufactura no maquilera creció a una tasa promedio anual de $1.87 \%$, la maquilera a una $9.45 \%$, mientras que la total fue del $-2.10 \%$; entre 2000-2009. Cuando la maquila disminuyó su peso en el empleo manufacturero del $53 \%$ al $43 \%$, la productividad no maquilera aumentó a una tasa promedio anual del $1.35 \%$, la maquilera al $3.77 \%$, y la total a una del $3.28 \%$. Esto último quiere decir que el aumento de la productividad manufacturera total ocurrido entre 2000 y 2009 está fuertemente influida por la caída del peso de la maquila en el empleo manufacturero.

Hay que insistir que la fórmula simplificada de los costos laborales unitarios reales, ya es posible apreciar que es falso que los menores salarios por trabajador sean sinónimo de tener los menores costos por unidad producida. Precisamente, una alta productividad puede permitir combinar altos salarios con los menores costos de producción, ya que esas altas remuneraciones se distribuyen en una mayor cantidad de bienes. Para los factores que influyen en la productividad ver nota número 27 previa.

Lo señalado en este punto coincide con lo encontrado por Salgado (2009) sobre el efecto negativo de la liberalización comercial sobre los salarios reales en El Salvador. Es importante aclarar, que una alta productividad puede permitir a una empresa tener los menores costos unitarios totales y laborales aunque tuviera salarios mayores que el resto. 

empresarios o el gobierno. Bajo el esquema neoliberal se han aplicado una serie de medidas que fortalecen el poder empresarial y reducen el de los trabajadores. Entre algunas de las medidas gubernamentales que impactan directamente en contra de los trabajadores están: el incremento de los salarios mínimos por debajo de la inflación, congelamiento de salarios de la administración pública en algunos períodos, permisividad frente al irrespeto a los derechos laborales en el sector público y privado por parte del Ministerio de Trabajo y privatizaciones de empresas públicas con destrucción de la organización sindical. Otras medidas que pueden impactar de manera indirecta son: liberalización comercial de sectores rezagados tecnológicamente, ya que al enfrentar problemas de rentabilidad se vuelve atractiva la estrategia de erosionar condiciones laborales; el fomento de industrias transnacionalizadas intensivas en mano de obra barata y con alta movilidad entre países, como la maquila, también disminuye el poder de negociación de los trabajadores. En la medida que se impone una correlación de fuerzas negativa para los trabajadores, aumenta su desempleo/subempleo o se empiezan a generalizar en distintas empresas condiciones laborales inferiores a las promedios en alguna industria, es un asunto de tiempo para que todas las empresas empiecen a erosionar también las condiciones.

No existe una única manera de deflactar los salarios nominales,

Sobre la estimación del $\mathrm{IHH}$ ver anexo 2. Según Durán y Álvarez (2008: 28), un IHH mayor que pudiendo usarse una variedad de índices según sean los aspectos que se buscan analizar. Si se está analizando los salarios como costos de producción, puede ser mejor utilizar índices de precios al productor, lo cual lo remite a la comparación de estos con los precios de los bienes y servicios que se utilizan como insumos y son producidos por las empresas -no limitados a bienes de consumo-. Si se analiza la capacidad adquisitiva de los salarios puede ser mejor utilizar los índices de precios al consumidor ya que así se subraya su carácter como demandante de bienes y servicios, que incluye bienes transables y no transables. Ahora bien, el hecho de usar índices de precios al productor o al por mayor, no quiere decir que los salarios sean determinados por los precios de los bienes intermedios o finales de los productores, ya que son los precios de los bienes de consumo los que juegan el papel determinante, si bien no mecánico.

Los salarios reales salvadoreños crecen levemente también si se utiliza el deflactor del PIB manufacturero, lo cual no es mostrado en los gráficos del presente trabajo.

Dado que ambos ICLUR utilizan la misma productividad para el caso de El Salvador, el ICLUR2 que utilizó los salarios reales deflactados por el IPC, que caen más que los deflactados por el IPM, es el que muestra una tendencia a un menor encarecimiento de los costos unitarios laborales. 


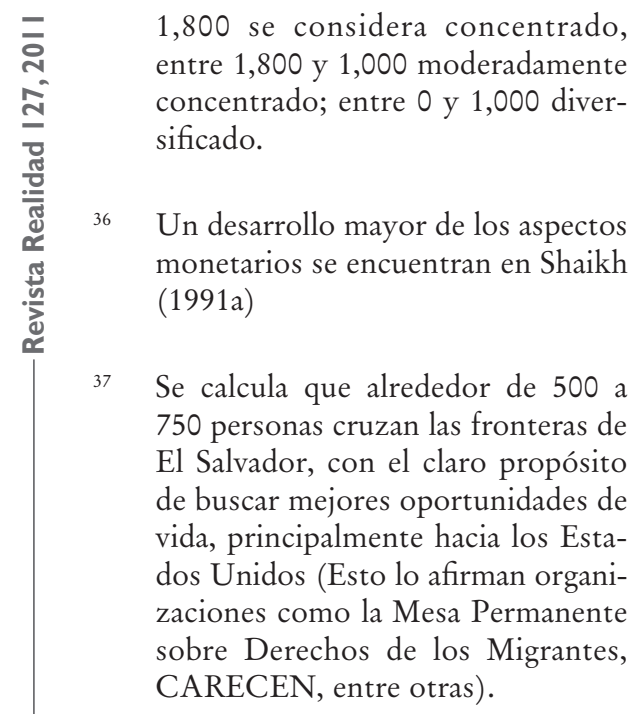

Las remesas no logran cubrir a plenitud las importaciones de bienes intermedios para el 2008, influidas por el alto costo del petróleo y sus derivados. Sin embargo, las importaciones de los bienes intermedios representaron en promedio el $89 \%$ de los ingresos de remesas entre 1999-2009.

Se han dejado los signos del cociente de los diferentes saldos comerciales sobre el PIB para dejar constancia de si el saldo de la cuenta externa es deficitaria (negativo) o superavitaria (positiva). 